\title{
Interaction of $M_{n+1} A X_{n}$ Phases with Oxygen- Poor, Static and Fast-Flowing Liquid Lead- Bismuth Eutectic
}

Thomas Lapauw ${ }^{a, b}{ }^{*}$, Bensu Tunca ${ }^{a, b}$, Jasper Joris ${ }^{b}$, Adrian Jianu $^{c}$, Renate Fetzer ${ }^{c}$, Alfons Weisenburger ${ }^{c}$, Jozef Vleugels ${ }^{a}$ and Konstantina Lambrinou ${ }^{b, d}$

a Department of Materials Engineering, KU Leuven, Kasteelpark Arenberg 44, 3001 Leuven, Belgium

${ }^{\mathrm{b}}$ SCK·CEN, Boeretang 200, $2400 \mathrm{Mol}$, Belgium

'Karlsruhe Institute of Technology (KIT), Institute for Pulsed Power and Microwave Technology, Hermann-von-Helmholtz-Platz 1, 73644 Eggenstein-Leopoldshafen, Germany

${ }^{\mathrm{d}}$ School of Computing and Engineering, University of Huddersfield, Queensgate, Huddersfield HD1 3DH, United Kingdom

* Corresponding author. Address: KU Leuven, Department of Materials Engineering, Kasteelpark Arenberg 44, B-3001 Leuven, Belgium. Tel.: + 3216 373605; fax: + 3216321990

E-mail address: thomas.lapauw@kuleuven.be (T. Lapauw)

\begin{abstract}
Select MAX phase-based ceramics were screened with respect to their potential susceptibility to environmentally-assisted degradation in an oxygen-poor liquid lead-bismuth eutectic (LBE) environment, both under static and fast-flowing exposure conditions. The majority of the MAX phases exposed to oxygen-poor ( $C_{O} \leq 2.2 \times 10^{-10}$ mass\%) static liquid LBE for at least $1000 \mathrm{~h}$ at $500^{\circ} \mathrm{C}$ showed exceptional chemical compatibility with the heavy liquid metal, i.e., no evidence of LBE dissolution attack was observed, despite the absence of a continuous oxide scale on the surface of the exposed MAX phase ceramics. The local LBE interaction observed only with the $\mathrm{Zr}$-rich MAX phases consisted in the partial substitution of $\mathrm{Al}$ by $\mathrm{Pb} / \mathrm{Bi}$ in the MAX phase crystal structure and the in-situ formation of $\mathrm{Pb} / \mathrm{Bi}$-containing solid solutions. Moreover, the interaction of Zr-based MAX phases with static liquid LBE was accompanied by the dissolution of parasitic intermetallic phases, which facilitated the further LBE ingress into the ceramic bulk. The erosion resistance of select MAX phase ceramics was also assessed in oxygen-poor $\left(C_{O} \approx\right.$ $5 \times 10^{-9}$ mass\%) fast-flowing $\left(v \approx 8 \mathrm{~m} / \mathrm{s}\right.$ ) liquid LBE for $1000 \mathrm{~h}$ at $500^{\circ} \mathrm{C}$. Despite the moderate LBE oxygen concentration, oxidation was the predominant corrosion mechanism, while no erosion damages were observed in the exposed MAX phase ceramics. The resistance of the MAX phase ceramics to both dissolution corrosion and erosion in contact with oxygen-poor
\end{abstract}


static and fast-flowing liquid LBE, respectively, was compared to that of the $316 \mathrm{~L}$ reference structural stainless steel.

Keywords: MAX phase; Lead-bismuth eutectic (LBE); Liquid metal corrosion; Erosion

\section{Highlights}

- Exposing 11 MAX phases to oxygen-poor, static LBE showed little or no interaction.

- The $L B E / Z r_{2} A I C$ interaction formed a new $Z_{2}(A l, P b, B i) C$ MAX phase solid solution.

- The $\mathrm{LBE} /(\mathrm{Zr}, \mathrm{Ti})_{n+1} \mathrm{AlC} \mathrm{C}_{n}$ interaction formed $(\mathrm{Zr}, \mathrm{Ti})_{n+1}(\mathrm{Al}, \mathrm{Pb}, \mathrm{Bi}) \mathrm{C}_{\mathrm{n}}$ solid solutions.

- $(\mathrm{Nb}, \mathrm{Zr})_{4} \mathrm{AlC}_{3}$ showed the best erosion resistance in oxygen-poor, fast-flowing LBE.

- MAX phases outperformed 316L stainless steels exposed to similar LBE conditions.

\section{Introduction}

One of the six Generation IV (Gen-IV) nuclear reactor concepts currently under development is based on a lead-cooled design [1], which is commonly referred to as Lead-Fast Reactor (LFR), since fast neutrons ( $>1 \mathrm{MeV}$ ) are used to sustain the fission reaction. This high-energy neutron spectrum ensures a higher fuel efficiency, enabling the usage of depleted uranium as nuclear fuel and the transmutation of long-lived nuclear waste [2]. A prerequisite for the deployment of Gen-IV LFRs is the availability of qualified nuclear materials that can withstand the anticipated harsh service environment [3]. One of the important concerns vis-à-vis the development of Gen-IV LFRs is the compatibility of both structural and fuel cladding materials with the primary $\mathrm{Pb}$-alloy coolant, such as liquid lead $(\mathrm{Pb})$ or lead-bismuth eutectic (LBE). A good compatibility guarantees that all reactor components maintain their structural integrity and the materials used for component construction retain their properties in contact with this heavy liquid metal (HLM). Under certain operating conditions, mainly determined by the temperature, time and HLM oxygen concentration, $C_{O}$, these requirements are not met by most nuclear steel grades, which may either suffer from liquid metal embrittlement (LME), as in the case of ferritic/martensitic steels [4], or from HLM dissolution attack, as in the case of austenitic stainless steels. HLM dissolution attack involves dissolution of highly-soluble steel alloying elements, such as $\mathrm{Ni}, \mathrm{Cr}$ and $\mathrm{Mn}$, LBE penetration into the steel bulk, and ferritisation of the dissolution-affected zone due to the removal of the austenite stabilizers $\mathrm{Ni}$ and $\mathrm{Mn}[5,6]$. One strategy to minimize liquid metal degradation phenomena relies on the use of corrosion inhibitors. These chemical substances are added in small amounts to the HLM and effectively decrease material loss rates by forming a protective film on the surface of both structural and fuel cladding steels [7]. Effective corrosion inhibitors that can be added to liquid LBE include oxygen, which forms a passivating oxide layer [8], or $\mathrm{Ti}$ or $\mathrm{Zr}$, which have a high affinity for the $\mathrm{N}$ and $\mathrm{C}$ in the steel, thus forming a protective nitride or carbide layer on the steel surface [9]. However, maintaining a homogeneous concentration of corrosion inhibitors in large reactor systems is challenging and local depletion might occur. 
An alternative corrosion mitigation approach aims at the development of innovative materials that are compatible with the HLM coolant over the entire range of nominal operation conditions and can withstand, to a certain extent, transient/accidental conditions. A group of ternary carbides and nitrides, known as the ' $M_{n+1} A X_{n}$ (MAX) phases', is considered to be intrinsically stable in contact with lead-based alloys. In $M_{n+1} A X_{n}$ compounds, $M$ corresponds to an early transition metal, $\mathrm{A}$ is an A-group element (commonly group 13 or 14 ), $\mathrm{X}$ is $\mathrm{C}$ or $\mathrm{N}$, and $\mathrm{n}$ is an integer equal to 1, 2 or 3 [10]. These nanolaminated materials combine properties typically associated either with ceramics and metals, i.e., they are elastically stiff and behave well at elevated temperatures $\left(>1000^{\circ} \mathrm{C}\right)$; they are good thermal and electrical conductors that are concomitantly damage-tolerant and machineable using conventional tools; and they exhibit a remarkable radiation tolerance above $600^{\circ} \mathrm{C}$ [10-13]. This combination of properties makes them attractive candidate materials for specific applications in HLM-cooled nuclear systems. The commercially available MAX phase-based materials Maxthal ${ }^{\circledR} 312$ and Maxthal ${ }^{\circledR}$ 211 are mainly composed of $\mathrm{Ti}_{3} \mathrm{SiC}_{2}$ and $\mathrm{Ti}_{2} \mathrm{AlC}$, respectively, but do contain some parasitic phases, such as $\mathrm{TiC}$ and $\mathrm{TiAl}_{3}$. The corrosion behaviour of these materials has been previously investigated in contact with liquid $\mathrm{Pb}$ and LBE [14-18]. An overview of the test conditions and the reported interaction is provided in Table 1. The four main test parameters are temperature, exposure time, HLM $C_{O}$, and HLM flow velocity. Overall, the reaction was very limited and consisted mainly of surface oxidation, resulting in the formation of a few micrometres-thick $\mathrm{TiO}_{2}$ (rutile) scale. The most severe degradation was observed in $\mathrm{Ti}_{2} \mathrm{AlC}$ after an exposure of $10,000 \mathrm{~h}$ at $650^{\circ} \mathrm{C}$ to static LBE with $C_{O} \approx 10^{-8}$ mass $\%$, where LBE was detected between the MAX phase grains, indicating that the intermetallic phase present in the commercial Maxthal ${ }^{\circledR}$ 211 grade partially dissolved [15]. This underlines the importance of minimizing the amount of parasitic phases in these materials. The MAX phases are considered as candidate structural materials for pump impeller components in $\mathrm{Pb}$ - and LBE-cooled reactors, such as the irradiation facility MYRRHA (multi-purpose hybrid research reactor for high-tech applications) currently under development at SCK·CEN, Belgium [19]. Pump impellers should operate reliably at system-specific temperatures (e.g., $\sim 480^{\circ} \mathrm{C}$ [18] and $\sim 270^{\circ} \mathrm{C}$ [20] for Pb- and LBEcooled reactor systems, respectively) in contact with a fast-flowing HLM. This implies that they should withstand liquid metal corrosion and, most importantly, erosion, as the HLM flow velocity is expected to reach $10-20 \mathrm{~m} / \mathrm{s}$ locally on the impeller surface [20]. Despite its importance for the envisaged pump impeller application, no dedicated study of the effect of fast-flowing LBE on the performance of MAX phase-based materials has so far been published.

Recently, Bentzel et al. studied the behaviour of several MAX phases in static liquid sodium, another Gen-IV coolant, up to $750^{\circ} \mathrm{C}$ for $168 \mathrm{~h}$ [21]. They reported that $\mathrm{Ti}_{3} \mathrm{SiC}_{2}, \mathrm{Ti}_{2} \mathrm{AIC}$ and $\mathrm{Cr}_{2} \mathrm{AlC}$ were stable, as well as their grain boundary phases. $\mathrm{Ti}_{3} \mathrm{AlC}_{2}$, however, showed signs of degradation along the grain boundaries and Al-depletion in the MAX phase grains [21]. Additionally, it should be mentioned that one of the methods to synthesize $\mathrm{Pb}$-containing MAX phases in the $1960 \mathrm{~s}-\mathrm{Pb}$ is a candidate A-element - consisted of exposing a powder mixture of $\mathrm{Ti}$ and $\mathrm{TiC}$ to liquid $\mathrm{Pb}$ at $850^{\circ} \mathrm{C}$ for $600 \mathrm{~h} \mathrm{[22].} \mathrm{This} \mathrm{fact} \mathrm{indicates} \mathrm{that} \mathrm{certain} \mathrm{MAX}$ 
phases might be even more stable in these metallic coolants than their corresponding binary carbides, e.g., TiC.

The primary goal of this study is to identify MAX phase compounds that do not suffer liquid metal degradation in oxygen-poor, fast-flowing liquid LBE, hereby targeting the harsh service conditions of pump impeller components. Therefore, the intrinsic stability of 11 different MAX phase-based materials was assessed first in oxygen-poor, static LBE. The selected exposure temperature was $500^{\circ} \mathrm{C}$, so as to be conservative for both liquid $\mathrm{Pb}$ and LBE coolants, while the tests lasted for at least $1000 \mathrm{~h}$, which is a standard exposure time for initial material screening. The set of tested materials comprised the commercially available Maxthal ${ }^{\circledR} 312$ and Maxthal ${ }^{\circledR}$ 211 grades, as well as lab grades of MAX phase ternary carbides and solid solutions thereof. $\mathrm{Ti}, \mathrm{Zr}$ and $\mathrm{Nb}$ were selected as M-elements, as these elements have small fast neutron crosssections [23]. Moreover, this work reports, for the first time, on the performance of MAX phases in contact with poorly oxygenated, fast-flowing liquid LBE at $500^{\circ} \mathrm{C}$ for $1000 \mathrm{~h}$. The latter exposure condition is particularly suited to assess the erosion/corrosion behaviour of the tested MAX phase materials. The performance of the MAX phase-based ceramics is invariably compared with that of a reference structural steel, i.e., the $316 \mathrm{~L}$ stainless steel, under similar exposure conditions. 
Table 1. Overview of all MAX phase exposures to liquid $\mathrm{LBE}$ and $\mathrm{Pb}$ reported in literature.

\begin{tabular}{|c|c|c|c|c|c|c|c|}
\hline MAX phase & HLM & $\mathbf{T}\left({ }^{\circ} \mathrm{C}\right)$ & Time (h) & $C_{o}$ (mass\%) & Flow Condition & Reported Interaction & Ref. \\
\hline \multirow{6}{*}{$\mathrm{Ti}_{3} \mathrm{SiC}_{2}$} & LBE & 700 & 1000 & $5 \times 10^{-6}$ & Static & No interaction observed & [14] \\
\hline & LBE & $550 / 650$ & 3000 & $10^{-6} / 10^{-8(*)}$ & Static & $\mathrm{TiO}_{2}$ (rutile) formation & [16] \\
\hline & LBE & $550 / 650 / 700$ & $\begin{array}{l}1000 / 3000 / \\
5000 / 10,000\end{array}$ & $10^{-6} / 10^{-8}$ & Static & $\begin{array}{l}\mathrm{TiO}_{2} \text { (rutile) formation - Local } \\
\text { surface disintegration }\end{array}$ & [15] \\
\hline & $\mathrm{Pb}$ & $650 / 800$ & 1000 & $10^{-12}$ & Natural convection & No interaction observed & [17] \\
\hline & $\mathrm{Pb}$ & $550 / 600 / 750$ & $500 / 2000 / 4000$ & $10^{-6} / 10^{-8(*)}$ & Static & $\mathrm{TiO}_{2}$ (rutile) formation & [16] \\
\hline & $\mathrm{Pb}$ & 500 & 2000 & $10^{-6}$ & $1 \mathrm{~m} / \mathrm{s}$ & Indication of thin oxide scale & [18] \\
\hline \multirow[t]{2}{*}{$\mathrm{Ti}_{2} \mathrm{AlC}$} & LBE & $550 / 650 / 700$ & $\begin{array}{l}1000 / 3000 / \\
5000 / 10,000\end{array}$ & $10^{-6} / 10^{-8}$ & Static & $\begin{array}{c}\mathrm{TiO}_{2} \text { (rutile) } \& \mathrm{Al}_{2} \mathrm{O}_{3} \text { formation at } \\
\mathrm{C}_{\mathrm{O}} \approx 10^{-6} \text { mass } \% \text { - Dissolution of } \\
\text { parasitic phases at } \mathrm{C}_{0} \approx 10^{-8} \\
\text { mass } \% \text { and } \mathrm{T}=650-700^{\circ} \mathrm{C}\end{array}$ & [15] \\
\hline & $\mathrm{Pb}$ & $650 / 800$ & 1000 & $10^{-12}$ & Natural convection & $\begin{array}{l}\text { No interaction observed with a } \\
\text { freshly machined surface }\end{array}$ & [17] \\
\hline
\end{tabular}

(*) HLM oxygen content calculated as in [24] 


\section{Experimental Procedure}

\subsection{Exposures to Static LBE}

Commercial Maxthal ${ }^{\circledR} 312$ (nominally, $\mathrm{Ti}_{3} \mathrm{SiC}_{2}$ ) and Maxthal ${ }^{\circledR} 211$ (nominally, $\mathrm{Ti}_{2} \mathrm{AIC}$ ) provided by Kanthal $A B$, Sweden, and a set of lab-made MAX phase grades were exposed to static liquid LBE at $500^{\circ} \mathrm{C}$. Table 2 provides the list of MAX phase ceramics exposed to static LBE. For most of these materials, the synthesis procedure and as-produced material characterization has already been reported in literature. Additionally, $\mathrm{Ti}_{3} \mathrm{AlC}_{2},(\mathrm{Ti}, \mathrm{Nb})_{2} \mathrm{AIC}, \mathrm{Nb}_{2} \mathrm{AIC}$ and $\mathrm{Nb}_{4} \mathrm{AlC}_{3}$ discs were produced using a similar powder-metallurgical synthesis route similar to that reported in [25]; for this purpose, Ti (Chemetall, Grade $\mathrm{S},<8 \mu \mathrm{m}), \mathrm{Nb}$ (HC Starck, $<45 \mu \mathrm{m}), \mathrm{Al}(\mathrm{AEE},<5 \mu \mathrm{m})$ and $C$ (Asbury, $<5 \mu \mathrm{m}$ ) starting powders were mixed in near-stoichiometric ratios. The raw powder mixtures were first pre-compacted in a graphite die at $30 \mathrm{MPa}$ and then spark plasma sintered at $1400,1500,1600$ and $1650^{\circ} \mathrm{C}$, respectively, under a load of $60 \mathrm{MPa}$ for $5 \mathrm{~min}$.

The MAX phase exposures to static LBE were carried out at SCK $\cdot C E N$, employing a test setup presented in Fig. 1a and previously described by Lambrinou et al. [6]. The setup consisted of a stainless steel autoclave with an inner alumina $\left(\mathrm{Al}_{2} \mathrm{O}_{3}\right)$ liner preventing contamination of the liquid LBE bath due to the dissolution of steel alloying elements from the autoclave walls. Temperature and LBE oxygen concentration were monitored during all exposures by a thermocouple type $\mathrm{K}$ and an electrochemical oxygen sensor $\left(\mathrm{Bi} / \mathrm{Bi}_{2} \mathrm{O}_{3}\right.$ reference electrode [26]), respectively. The LBE oxygen concentration was calculated as follows [6]:

$$
\begin{aligned}
& \Delta U-\Delta U_{t h}=-0.34756+2.5217 \times 10^{-4} \cdot T-4.3087 \times 10^{-5} \cdot T \cdot \ln C_{O} \\
& \Delta U_{t h}=-6.91 \times 10^{-3}+1.762 \times 10^{-5} \cdot T
\end{aligned}
$$

where $\Delta U$ is the electric potential difference measured by the electrochemical oxygen sensor in $\mathrm{V}, \Delta U_{t h}$ is the thermoelectric potential between stainless steel tube and Mo lead wire in $\mathrm{V}$, $T$ is the absolute temperature in $\mathrm{K}$, and $C_{O}$ is the LBE oxygen concentration in mass\%.

The aim of the performed exposures to static LBE was to assess the inherent resistance of the MAX phase ceramics to LBE dissolution attack. Therefore, the selected test conditions involved material exposure to oxygen-poor, static $\operatorname{LBE}\left(C_{O}<10^{-8}\right.$ mass\%) at a high temperature $\left(500^{\circ} \mathrm{C}\right)$, so as to suppress the formation of protective oxide scales on the surface of the MAX phase samples, thus facilitating dissolution corrosion. The concentration of dissolved oxygen in the liquid LBE bath ( $\sim 5 \mathrm{~kg}$ of freshly molten LBE) was maintained low throughout all exposures by continuously feeding a reducing gas (HYTEC 5: Ar-5\% $\mathrm{H}_{2}$, Rapid Industrial Gases Ltd., UK) (Fig. 1a). These test conditions favour the occurrence of LBE dissolution attack in various nuclear grade structural steels, such as $316 \mathrm{~L}$ stainless steels or similar $[6,27]$. One side of each MAX phase disc was mirror polished and studied by scanning electron microscopy (SEM) prior to the LBE exposure. Pieces of these discs were mounted on graphite plates using Mo wires (Fig. 1b); the graphite plates were used to maintain the MAX phases submerged in the LBE bath throughout the tests. Pictures of one graphite plate loaded with MAX phase samples are shown in Fig. 1b and Fig. 1c before and after the 3500-h exposure, respectively. In total, three different 
screening exposures were performed, i.e., one for $3500 \mathrm{~h}$ and two for $1000 \mathrm{~h}$. The exposure conditions ( $T$, time and $C_{O}$ ) are summarised in Table 2. Fig. 2 shows the evolution of the LBE oxygen concentration as function of the exposure time. The 3500-h exposure shows a discontinuity around $500 \mathrm{~h}$, which can be associated with lowering the bath temperature to remove a sample sub-set for analysis. Since the MAX phase samples were removed at $\sim 200^{\circ} \mathrm{C}$, the oxygen uptake from the liquid LBE during the brief setup opening was minimal, with the LBE oxygen concentration quickly stabilising at $C_{O} \approx 10^{-10}$ mass $\%$ under the continuous purging with $\mathrm{Ar}-5 \% \mathrm{H}_{2}$ for the remainder of this exposure.

\subsection{Exposure to Fast-Flowing LBE}

The erosion resistance of select MAX phase ceramics was assessed in the CORELLA (Corrosion Erosion Test Facility for Liquid Lead Alloy) facility at KIT, Germany, in contact with fast-flowing LBE. A detailed description of this setup is provided in [30]. The CORELLA facility consists of a fast-rotating inner cylinder (rotation speed $\leq 2000 \mathrm{rpm}$ ) inside a container (test chamber) filled with the molten $\mathrm{Pb}$-alloy, i.e., fresh, uncontaminated LBE in the present study. The flow velocity experienced by the samples depends on the angular velocity and radial distance from the centre, and the achievable LBE flow velocities can exceed $10 \mathrm{~m} / \mathrm{s}$. Detailed computational fluid dynamics (CFD) calculations on the flow patterns and HLM velocity may be found in [30]. Prior to actual testing, the liquid LBE was stored in another container (conditioning chamber), where it was conditioned in terms of $C_{O}$. Table 2 provides an overview of the tested MAX phase ceramics together with the exact test conditions. During testing, both $T$ and $C_{O}$ were monitored with thermocouple type $\mathrm{K}$ and electrochemical oxygen sensor $\left(\mathrm{Bi} / \mathrm{Bi}_{2} \mathrm{O}_{3}\right.$ reference electrode), respectively. The LBE $C_{O}$ profile, for the exposure at the CORELLA facility, is also given in Fig. 2 as function of time. Due to a problem with data acquisition, the LBE $C_{O}$ data from the first 300 $\mathrm{h}$ are missing. The tested MAX phase ceramics have been exposed to oxygen-containing $\left(C_{O}\right.$ $\approx 5 \times 10^{-9}$ mass $\left.\%\right)$, fast-flowing $(\mathrm{v} \approx 8 \mathrm{~m} / \mathrm{s})$ liquid $\mathrm{LBE}$ at $500^{\circ} \mathrm{C}$.

The MAX phase specimens had a thickness of $1.5 \mathrm{~mm}$, a width of $15 \mathrm{~mm}$, and a length of 45 $60 \mathrm{~mm}$. The front surface, facing the highest LBE flow velocity, was ground using a diamond grinding wheel (D46 SW-50-X2, TechnoDiamond). One sample of $(\mathrm{Nb}, \mathrm{Zr})_{4} \mathrm{AIC}{ }_{3}$ was machined by conventional milling to demonstrate the material's machinability and to assess the effect of higher surface roughness on erosion resistance. The MAX phase ceramics were tested together with the MYRRHA reference structural steel, i.e., the $316 \mathrm{~L}$ austenitic stainless steel grade. For this purpose, a $316 \mathrm{~L}$ steel specimen, made of the solution-annealed EUROTRANS-DEMETRA industrial-size plate (15 mm in thickness [6]; designated 316 LA in Table 2), was added to the set of specimens tested in the CORELLA. Before and after the exposure to fast-flowing LBE, the surface condition of all specimens was examined by profilometry (Talysurf-120L, Taylor Hobson). After the exposure, the solidified LBE residues were removed from the samples. The largest amount of LBE was removed in the liquid state by briefly immersing the samples in hot oil (Biskin sunflower and colza oil, $190^{\circ} \mathrm{C}, \sim 30 \mathrm{sec}$ ). Subsequently, the remaining LBE was removed in an equivolumetric solution of ethanol $\left(\mathrm{C}_{2} \mathrm{H}_{5} \mathrm{OH}\right)$, hydrogen peroxide $\left(\mathrm{H}_{2} \mathrm{O}_{2}\right)$ and acetic acid $\left(\mathrm{CH}_{3} \mathrm{COOH}\right)$. 


\subsection{Post-Exposure Characterization}

All materials listed in Table 2 were cross-sectioned and their microstructure was studied in detail prior to and after exposure, using SEM (JSM-6610LV, JEOL, Japan; XL30-FEG \& Nova 450 NanoSEM, FEl, The Netherlands) equipped with energy dispersive X-ray spectroscopy (EDS; Bruker and EDAX). Quantitative elemental analysis of select areas of interest was performed by electron probe microanalysis (EPMA; JXA-8530F, JEOL Ltd., Japan; operating conditions: 15 $\mathrm{kV}$ accelerating voltage, $15 \mathrm{nA}$ beam current) using wavelength-dispersive $X$-ray spectroscopy (WDS). The reported chemical composition values are an average of 5 points, and the standard deviation is in the order of $1 \mathrm{wt} \%$. Backscattered electron diffraction (EBSD; Hikari XP EBSD camera, EDAX, USA, on a FEI Nova NanoSEM 450, FEI, USA) was also employed to ensure that the MAX phase crystal structure was maintained in LBE-affected zones. A $200 \mathrm{kV}$ transmission electron microscope (TEM; JEOL ARM200F, Japan) equipped with EDS and high-angle annular dark field (HAADF) detector was used in the scanning transmission electron microscopy (STEM) mode for elemental mapping and selected area diffraction (SAED) studies. TEM thin foils were prepared from specific areas of interest in the LBE-affected MAX phase ceramics by means of focused ion beam (FIB; Nova 600 NanoLab, Dual Beam SEM/FIB, FEI, The Netherlands), using $30 \mathrm{kV} \mathrm{Ga}$ ions for milling and $5 \mathrm{kV}$ for the final cleaning step. 
Table 2. Overview of the tested materials and their corresponding exposure conditions.

\begin{tabular}{|c|c|c|c|c|c|c|}
\hline Material & $\begin{array}{c}\text { Parasitic Phases } \\
\text { (XRD Data) }\end{array}$ & Material Ref. & $\mathrm{T}\left({ }^{\circ} \mathrm{C}\right)$ & Time (h) & Plot in Fig. 2 & Flow Condition \\
\hline $\begin{array}{c}\text { Maxthal }{ }^{\circledR} 312 \\
\left(\mathrm{Ti}_{3} \mathrm{SiC}_{2}\right)\end{array}$ & $\mathrm{TiC}$ & $\begin{array}{c}\text { Kanthal } A B \text {, Sweden } \\
{[31]}\end{array}$ & 500 & 3500 & (1) & Static \\
\hline $\begin{array}{c}\text { Maxthal }^{\circledR} 211 \\
\left(\mathrm{Ti}_{2} \mathrm{AlC}+\mathrm{Ti}_{3} \mathrm{AIC} \mathrm{C}_{2}\right)\end{array}$ & $\mathrm{TiAl}_{3}$ & $\begin{array}{c}\text { Kanthal } A B \text {, Sweden } \\
{[31]}\end{array}$ & 500 & 3500 & (1) & Static \\
\hline$(\mathrm{Ti}, \mathrm{Nb})_{2} \mathrm{AlC}$ & $\mathrm{TiAl}_{3}, \mathrm{Al}_{2} \mathrm{O}_{3}$ & / & 500 & 3500 & (1) & Static \\
\hline $\mathrm{Ti}_{3} \mathrm{AlC}_{2}$ & / & / & 500 & 3500 & (1) & Static \\
\hline $\mathrm{Nb}_{2} \mathrm{AlC}$ & $\mathrm{Al}_{2} \mathrm{O}_{3}$ & / & 500 & 3500 & (1) & Static \\
\hline $\mathrm{Nb}_{4} \mathrm{AlC}_{3}$ & $\mathrm{NbAl}_{3}, \mathrm{Al}_{2} \mathrm{O}_{3}$ & I & 500 & 3500 & $(1)$ & Static \\
\hline \multirow[t]{2}{*}{$\left(\mathrm{Nb}_{0.85}, \mathrm{Zr}_{0.15}\right)_{4} \mathrm{AlC}_{3}{ }^{(*)}$} & \multirow{2}{*}{$\mathrm{Al}_{2} \mathrm{O}_{3}$} & \multirow[t]{2}{*}{ [32] } & 500 & 1000 & (2) & Static \\
\hline & & & 500 & 1000 & (3) & $\mathrm{v} \approx 8 \mathrm{~m} / \mathrm{s}$ \\
\hline \multirow{2}{*}{$\mathrm{Zr}_{2} \mathrm{AIC}$} & \multirow{2}{*}{$\mathrm{ZrC}$} & \multirow[t]{2}{*}{ [33] } & 500 & 1000 & (2) & Static \\
\hline & & & 500 & 1000 & (3) & $v \approx 8 \mathrm{~m} / \mathrm{s}$ \\
\hline \multirow{2}{*}{$\mathrm{Zr}_{3} \mathrm{AlC}_{2}$} & \multirow{2}{*}{$\mathrm{ZrC}, \mathrm{ZrAl}_{2}$} & \multirow{2}{*}[34]{} & 500 & 1000 & (2) & Static \\
\hline & & & 500 & 1000 & (3) & $\mathrm{v} \approx 8 \mathrm{~m} / \mathrm{s}$ \\
\hline
\end{tabular}




\begin{tabular}{ccccccc}
\hline $\begin{array}{c}\left(\mathbf{Z r}_{0.8}, \mathbf{T i}_{0.2}\right)_{\mathbf{2}} \mathbf{A l C} \& \\
\left(\mathbf{Z r}_{0.8}, \mathbf{T i}_{0.2}\right)_{\mathbf{3}} \mathbf{A l C}\end{array}$ & $(\mathrm{Zr}, \mathrm{Ti}) \mathbf{C}$ & {$[35]$} & 500 & 1000 & $(2)$ & Static \\
\hline $\mathbf{T i}_{2} \mathbf{S n C}$ & $\mathrm{Sn}, \mathrm{TiC}$ & {$[25]$} & 500 & 1000 & $(4)$ & Static \\
\hline 316L SA \& 316L CW & $/$ & {$[6]$} & 500 & $1000 / 3282$ & $/$ & Static \\
\hline 316L SA & $/$ & {$[6]$} & 500 & 1000 & $(3)$ & $\mathrm{v} \approx 8 \mathrm{~m} / \mathrm{s}$
\end{tabular}

$\overline{(*)}$ Two surface conditions were tested in the CORELLA, i.e., ground and conventionally milled; SA = solution-annealed; CW = cold-worked 


\section{Results and Discussion}

\subsection{Exposures to Static LBE}

An overview of the microstructure of the pristine MAX phase ceramics is provided in Fig. 3. The constituent phases are indicated on the micrographs and listed in Table 2. In most grades, the MAX phase grains can be easily identified by their lamellar shape, which reflects their hexagonal crystal structure with large $c / a$ ratio and with the $c$-axis oriented perpendicular to the longer direction. The backscattered electron (BSE) images of Fig. 3 indicate that parasitic phases were present in nearly all MAX phase-based ceramics. Only in $\mathrm{Ti}_{3} \mathrm{AlC}_{2}$, no evidence of another phase was found. Three types of parasitic phases could be identified: oxides, (pseudo-)binary carbides and A-rich compounds. Alumina $\left(\mathrm{Al}_{2} \mathrm{O}_{3}\right)$ particles were detected in all Nb-containing materials and resulted from the aluminothermal reduction of $\mathrm{Nb}_{2} \mathrm{O}_{5}$, which was an impurity in the $\mathrm{Nb}$ starting powder. $\mathrm{Al}_{2} \mathrm{O}_{3}$ particles were small $(<5 \mu \mathrm{m})$ and well-dispersed in the material microstructure: they were present at grain boundaries or inside the grains, as in the case of the $(\mathrm{Ti}, \mathrm{Nb})_{2} \mathrm{AlC}$ and $\left(\mathrm{Nb}_{0.85}, \mathrm{Zr}_{0.15}\right)_{4} \mathrm{AlC} \mathrm{C}_{3}$ ceramics (Fig. 3). These small oxide grains did not jeopardize the material's machinability, as demonstrated for milled $\left(\mathrm{Nb}_{0.85}, \mathrm{Zr}_{0.15}\right)_{4} \mathrm{AlC}_{3}$. Moreover, they have been reported to improve the flexural strength and fracture toughness of MAX phase ceramics [36]. The (pseudo-)binary carbides were present in Maxthal ${ }^{\circledR} 312$ (TiC), in the Zr-rich ceramics ( $\mathrm{ZrC}$ and $(\mathrm{Zr}, \mathrm{Ti}) \mathrm{C})$ and in $\mathrm{Ti}_{2} \mathrm{SnC}(\mathrm{TiC})$. These carbides were the main competing phases during MAX phase synthesis and their complete elimination was challenging, especially in the case of the $\mathrm{Zr}$-rich MAX phases. The carbide grains were very fine (in the micrometre to submicrometre range for $\left.\left(\mathrm{Zr}_{\mathrm{r}} \mathrm{Ti}\right) \mathrm{C}\right)$ and preferred to cluster together between the MAX lamellae. The third group of parasitic phases comprised A-rich compounds. These were typically intermetallics, i.e., TiAl, $\mathrm{NbAl}_{3}$ and $\mathrm{ZrAl}_{2}$, or occasionally metallic $\mathrm{A}$, such as $\mathrm{Sn}$, in the case of $\mathrm{Ti}_{2} \mathrm{SnC}$. These phases were mainly present at grain boundaries and in triple points. They have been reported to be most susceptible to liquid metal attack and, hence, are considered as most detrimental for the corrosion resistance of MAX phase-based materials [15]. This statement was confirmed for the 11 materials exposed to static liquid LBE in this work.

An overview of the 11 MAX phase ceramics after exposure to static LBE is given in Fig. 4. The BSE images show the MAX/LBE interface at the mirror-polished side. The bright phase on top of all materials are solidified LBE residues that create a strong compositional contrast with the MAX phase materials due to large differences in the respective mean atomic numbers. A first observation is that all polished surfaces remained intact, leaving the MAX/LBE interfaces flat. This is in stark contrast with the dissolution corrosion damages observed in $316 \mathrm{~L}$ stainless steels exposed to similar test conditions. Examples of such damages are presented in Fig. 5 for two $316 \mathrm{~L}$ steel heats that were previously exposed by Lambrinou et al. [6] to oxygen-poor $\left(C_{O}<\right.$ $2.2 \times 10^{-8}$ mass\%), static liquid $L B E$, at $500^{\circ} \mathrm{C}$, for $1000 \mathrm{~h}$ and $3282 \mathrm{~h}$. The two steel heats were: one solution-annealed heat (here designated $316 \mathrm{~L} \mathrm{SA}$; also exposed to fast-flowing LBE in this work) and a cold-worked heat (here designated 316L CW; described as $316 \mathrm{LH} 1$ in Ref. [6]). Both $316 \mathrm{~L}$ steel heats are included in the list of tested materials presented in Table 2. As shown in Fig. 5, dissolution corrosion damages in $316 \mathrm{~L}$ stainless steels exposed to comparable conditions 
are much more severe, especially for cold-worked steels (reaching locally $\sim 350 \mu \mathrm{m}$ in the $316 \mathrm{~L}$ CW steel), than in the MAX phase-based ceramics. Moreover, LBE penetrates into 316L stainless steels by following preferred ingress paths in the steel microstructure (e.g., grain boundaries, deformation twin boundaries, etc.) and the steel/LBE interaction is catastrophic, i.e., the LBEaffected zones lose their load-bearing capacity. The dissolution corrosion behaviour of $316 \mathrm{~L}$ stainless steels has been previously addressed by Lambrinou et al. [6] and does not merit further analysis here, except for comparison with the behaviour of the MAX phases. In contrast with the adverse effects of LBE dissolution attack on $316 \mathrm{~L}$ steels, the LBE penetration into the MAX phases occurs in an orderly manner, without destroying the MAX phase crystal structure and, presumably, without severe - if any - loss in load-bearing capacity. Even though the latter statement should still be confirmed experimentally, this work provides ample evidence that the MAX phase crystal structure is preserved during the observed LBE ingress into Zr-based MAX phases (the latter being the only MAX phase compounds that showed interaction with liquid LBE). The interaction of Zr-based MAX phases with oxygen-poor, static LBE will be extensively addressed later in the text.

The following materials did not show any sign of interaction with the liquid LBE: Maxthal ${ }^{\circledR} 312$, Maxthal ${ }^{\circledR} 211,(\mathrm{Ti}, \mathrm{Nb})_{2} \mathrm{AlC}, \mathrm{Nb}_{2} \mathrm{AlC}, \mathrm{Nb}_{4} \mathrm{AlC}{ }_{3}$ and $\left(\mathrm{Nb}_{0.85}, \mathrm{Zr}_{0.15}\right)_{4} \mathrm{AlC}$. No LBE traces were detected in the material bulk for these grades, and any impression of sub-surface LBE presence in some of these materials, i.e., in Maxthal ${ }^{\circledR} 211$ and (Ti,Nb) ${ }_{2} \mathrm{AlC}$ (Fig. 4), can be attributed to local LBE smearing during polishing of the metallographic cross-sections. Moreover, the very low LBE $C_{O}$ during these exposures did not form an oxide scale resolvable by SEM; this could be attributed to one of the following two reasons: either these MAX phase ceramics were intrinsically stable to LBE dissolution attack or they were protected by a nanometric protective oxide film covering the specimen surface. For example, $\mathrm{Al}_{2} \mathrm{O}_{3}$ and $\mathrm{SiO}_{2}$ thin films could be protective at the reported exposure conditions, as both $\mathrm{Al}_{2} \mathrm{O}_{3}$ and $\mathrm{SiO}_{2}$ are thermodynamically stable at $C_{O}<<10^{-15}$ mass $\%$ at $500^{\circ} \mathrm{C}$ in liquid LBE [37]. In order to examine whether the presence of a nanometric (not resolvable by SEM), protective oxide film prevented the occurrence of LBE dissolution attack, FIB/TEM/EDS work was performed on non-attacked by LBE areas of the following MAX phase ceramics: $\mathrm{Zr}_{2} \mathrm{AlC},\left(\mathrm{Zr}_{0.8}, \mathrm{Ti}_{0.2}\right)_{\mathrm{n}+1} \mathrm{AlC}_{\mathrm{n}},\left(\mathrm{Nb}_{0.85}, \mathrm{Zr}_{0.15}\right)_{4} \mathrm{AlC}_{3}$ and Maxthal ${ }^{\circledR} 211$ (nominally, $\mathrm{Ti}_{2} \mathrm{AIC}$ ). Specimen selection for this detailed work aimed at providing an explanation for the good compatibility of MAX phase compounds in the $(\mathrm{Zr}, \mathrm{Ti}, \mathrm{Nb})-\mathrm{Al}-\mathrm{C}$ system with oxygen-poor liquid LBE at $500^{\circ} \mathrm{C}$.

For the remaining ceramics, two degrees of interaction could be distinguished: the weakest interaction was observed for $\mathrm{Ti}_{3} \mathrm{AlC}_{2}$ and $\mathrm{Ti}_{2} \mathrm{SnC}$, with the $\mathrm{LBE}$ penetrating locally into grain boundaries. For $\mathrm{Ti}_{3} \mathrm{AlC}_{2}$, the interaction was very local with a maximum depth of $L B E$ penetration of $\sim 20 \mu \mathrm{m}$, while both the bulk of the MAX phase grains and the overall material integrity were not affected. A stronger interaction was observed for $\mathrm{Ti}_{2} \mathrm{SnC}$ : since $\mathrm{Sn}$ melts at $232^{\circ} \mathrm{C}$, this minor phase in the material was removed, dissolving into the liquid LBE. The homogeneous presence of $\mathrm{Pb}$ and $\mathrm{Bi}$ in the specimen suggests that liquid $\mathrm{LBE}$ percolated through the interconnected network of $\mathrm{Sn}$-rich areas into the material bulk, leaving the $\mathrm{Ti}_{2} \mathrm{SnC} \mathrm{MAX}$ phase grains intact. For both $\mathrm{Ti}_{3} \mathrm{AlC}_{2}$ and $\mathrm{Ti}_{2} \mathrm{SnC}$, the type of observed interaction is similar to that reported for $\mathrm{Ti}_{2} \mathrm{AlC}$ 
by Heinzel et al. [15], i.e., the intergranular LBE penetration resulted in LBE dissolution attack of the A-rich phase $\left(\mathrm{TiAl}_{3}\right)$, while the MAX phase grains remained unaffected. Differences in the liquid metal corrosion behaviour of the MAX phases and their (often unavoidable) parasitic phases is an additional reason for targeting high phase purity in MAX phase-based materials intended for HLM-cooled nuclear systems.

The most severe interaction was observed in the $\mathrm{Zr}$-rich MAX phase ceramics $\mathrm{Zr}_{2} \mathrm{AlC}_{1} \mathrm{Zr}_{3} \mathrm{AlC}_{2}$ and $\left(\mathrm{Zr}_{0.8}, \mathrm{Ti}_{0.2}\right)_{n+1} \mathrm{AIC}$. In these materials, the intermetallics at grain boundaries underwent $\mathrm{LBE}$ dissolution attack and even the MAX phase grains were affected by the HLM. The bright zones in these materials correspond to LBE-affected regions and can be easily distinguished from the unaffected (pseudo-)binary carbides, as illustrated in Fig. 6b for $\mathrm{ZrC}$ in $\mathrm{Zr}_{2} \mathrm{AlC}$ and in Fig. 9a for $(\mathrm{Zr}, \mathrm{Ti}) \mathrm{C}$ in $\left(\mathrm{Zr}_{0.8}, \mathrm{Ti}_{0.2}\right)_{\mathrm{n}+1} \mathrm{AlC} \mathrm{C}_{\mathrm{n}}$. Despite the observed MAX/LBE interaction, the specimen surface appeared intact and the specimens kept their structural integrity. No deterioration similar to that observed for $\mathrm{Ti}_{3} \mathrm{AlC}_{2}$ in liquid sodium ( $\mathrm{Na}$ ) was observed [21]. Moreover, the LBE-affected zone did not have uniform thickness and the LBE penetration depth could exceed locally 100 $\mu \mathrm{m}$, whereas no interaction was observed in adjacent regions, as shown in Fig. 6a for the $\mathrm{Zr}_{2} \mathrm{AlC}$ based ceramic. In an attempt to explain such localised differences in the corrosion behaviour of the $\mathrm{Zr}_{2}$ AIC-based MAX phase ceramic, a FIB foil was extracted from a non-affected material area and studied by TEM/STEM/EDS, and the results of this dedicated study will be discussed later in the text.

The propagation of the MAX/LBE interaction front is rather unusual: as shown for $\mathrm{Zr}_{2} \mathrm{AlC}$, the LBE penetration into the MAX phase grains occurs in a layered manner, resulting in a stripy grain pattern (Fig. 6c). Considering the nanolaminated crystal structure of the MAX phases, the planes of LBE penetration are most likely A-layers where $\mathrm{Al}$ is partially replaced by $\mathrm{Pb}$ and/or $\mathrm{Bi}$. Apart from the easy to understand LBE diffusion along the basal planes, LBE also diffuses almost perpendicular to the basal planes inside the MAX phase grains, as shown by the LBErich protrusions observed in a grain on the right hand-side of Fig. $6 c$ (pinpointed by arrow). The diffusion of $\mathrm{Pb}$ and $\mathrm{Bi}$ away from the basal planes in $\mathrm{Zr}_{2} \mathrm{AlC}$ is also confirmed by the EDS elemental maps in Fig. 7a. The Al-atoms that leave the MAX phase structure tend to segregate at grain boundaries, as shown by the Al-decorated grain boundaries of $\mathrm{LBE}$-affected $\mathrm{Zr}_{2} \mathrm{AIC}$ MAX phase grains in Fig. 7b. In this context, the work of Horlait et al. [38, 39] is of great interest: they investigated the possibility to stabilize the $\mathrm{Zr}_{2} \mathrm{AlC}$-structure by producing $\mathrm{M}$ - and A-site solid solutions, showing that both $\mathrm{Pb}$ and $\mathrm{Bi}$ could be introduced on the A-site, forming $\mathrm{Zr}_{2}\left(\mathrm{Al}_{0.35}, \mathrm{~Pb}_{0.65}\right) \mathrm{C}$ and $\mathrm{Zr}_{2}\left(\mathrm{Al}_{0.42}, \mathrm{Bi}_{0.58}\right) \mathrm{C}$, respectively. $\mathrm{The}_{\mathrm{Zr}} \mathrm{PbC}$ end-member is known since the 1960s [40], but it was not possible to synthesise $\operatorname{Zr}_{2} B i C$ [39]. Moreover, the attempt to synthesise $\mathrm{Zr}_{2}(\mathrm{~Pb}, \mathrm{Bi}) \mathrm{C}$ with a eutectic $\mathrm{Pb}$ :Bi ratio (atomic ratio $\left.\approx 45: 55\right)$ proved unsuccessful. In fact, $\mathrm{Bi}$ could not be incorporated in the MAX phase structure, and only $\mathrm{Zr}_{2} \mathrm{PbC}$ was produced [38]. In the present work, all three A-elements were detected in the LBE-affected MAX phase lamellae, suggesting the synthesis of new $\mathrm{Zr}_{n+1}(\mathrm{Al}, \mathrm{Pb}, \mathrm{Bi}) \mathrm{C}_{n}$ and $\left(\mathrm{Zr}_{0.81} \mathrm{Ti}_{0.2}\right)_{n+1}(\mathrm{Al}, \mathrm{Pb}, \mathrm{Bi}) \mathrm{C}_{n} \mathrm{MAX}$ phase solid solutions. 
In order to verify whether the MAX phase structure was maintained over large parts of the LBEaffected zones, EBSD was employed, as shown in Fig. $6 \mathrm{~d}$ for the $\mathrm{Zr}_{2} \mathrm{AlC}$-based ceramic. The use of EBSD in conjunction with EDS elemental mapping of the LBE-affected zone (Fig. 6e) showed that LBE-affected grains could still be indexed as the $\mathrm{Zr}_{2} \mathrm{AIC}$ MAX phase compound. In order to confirm beyond any doubt the retention of the MAX phase crystal structure, despite the incorporation of $\mathrm{Pb} / \mathrm{Bi}$ atoms, SAED was employed on FIB foils lifted out of the LBE-affected zone. The proof of the retention of the MAX phase crystal structure is provided in Fig. $6 \mathrm{f}$, which confirms that a MAX phase grain in the centre of the LBE-affected zone of the $\mathrm{Zr}_{2} \mathrm{AlC}$-based ceramic has indeed the $\mathrm{Zr}_{2} \mathrm{AIC}$ crystal structure (the SAED pattern shown in Fig. $6 \mathrm{f}$ is the $2 \overline{11} 0$ zone axis of $\left.\mathrm{Zr}_{2} \mathrm{AlC}\right)$. The lattice parameters $a$ and $c$ of the $\mathrm{Zr}_{2}(\mathrm{Al}, \mathrm{Pb}, \mathrm{Bi}) \mathrm{C}$ solid solution are estimated based on SAED patterns from 7 grains in the LBE-affected zone and are compared to those of related $\mathrm{Zr}$-based MAX phase compounds in Table 3. In comparison with $\mathrm{Zr}_{2} \mathrm{AIC}$, the lattice expanded significantly due to the incorporation of $\mathrm{Pb}$ and $\mathrm{Bi}$ atoms. This can be attributed to the larger atomic radius of these two atoms as compared to $\mathrm{Al}$ [39]. The expansion along the $a$ direction is comparable to that observed for the Bi-containing solid solution $\mathrm{Zr}_{2}\left(\mathrm{Al}_{0.42}, \mathrm{Bi}_{0.58}\right) \mathrm{C}$ [39] and $\mathrm{Zr}_{2} \mathrm{PbC}$ [41]. On average, the lattice expands more in the $c$ direction (2.5\% as compared to $\mathrm{Zr}_{2} \mathrm{AIC}$ ) and the c-axis is notably larger than in any other reported 211 compound [42]. The retention of the MAX phase crystal structure in LBE-affected areas was also confirmed by SAED and STEM/EDS for the exposed $\left(\mathrm{Zr}_{0.8,}, \mathrm{Ti}_{0.2}\right)_{n+1} \mathrm{AlC}_{\mathrm{n}}$ ceramic: the presence of $\mathrm{Pb} / \mathrm{Bi}$ in both 211 and $312 \mathrm{MAX}$ phase grains in this material (Fig. 9d) did not alter the crystal structure (the SAED patterns in Fig. $9 \mathrm{~b}$ show the $2 \overline{11} 0$ zone axis of the 211 and 312 MAX phases for two of the LBE-affected grains).

Table 3. Lattice parameters ( $\mathrm{LPs})$ for $\mathrm{Zr}_{2}(\mathrm{Al}, \mathrm{Pb}, \mathrm{Bi}) \mathrm{C}$ and related $\mathrm{MAX}$ phase compounds.

\begin{tabular}{ccccc}
\hline $\mathbf{L P}$ & $\mathbf{Z r}_{\mathbf{2}}\left(\mathbf{A l}_{\mathbf{0 . 6 5}}, \mathbf{P b}_{\mathbf{0 . 1 6}}, \mathbf{B i}_{\mathbf{0 . 1 9}}\right) \mathbf{C}$ & $\mathbf{Z r}_{\mathbf{2}} \mathbf{A I C}[\mathbf{3 3 ]}$ & $\mathbf{Z r}_{\mathbf{2}} \mathbf{P b C}[\mathbf{4 1}]$ & $\mathbf{Z r}_{\mathbf{2}}\left(\mathbf{A l}_{\mathbf{0 . 4 2}}, \mathbf{B i}_{\mathbf{0 . 5 8}}\right) \mathbf{C}[\mathbf{3 9 ]}$ \\
\hline $\boldsymbol{a}(\boldsymbol{\AA})$ & $3.37 \pm 0.03$ & $3.32 \pm 2 \times 10^{-4}$ & 3.38 & $3.34 \pm 5 \times 10^{-3}$ \\
\hline $\boldsymbol{c}(\boldsymbol{\AA})$ & $14.93 \pm 0.35$ & $14.57 \pm 4 \times 10^{-4}$ & 14.67 & $14.51 \pm 2 \times 10^{-2}$ \\
\hline
\end{tabular}

The $\mathrm{Zr}_{2} \mathrm{AlC}$ ceramic showed the deepest LBE penetration $(\sim 150 \mu \mathrm{m})$; the latter was mainly, but not exclusively, concentrated at specimen corners, suggesting that the local concentration of (presumably tensile) stresses at these sites might have facilitated the LBE ingress into the bulk. The $\mathrm{Zr}_{2} \mathrm{AIC} / \mathrm{LBE}$ interaction front appeared rather diffuse and was characterised by a gradual increase in the $\mathrm{Pb}$ and $\mathrm{Bi}$ contents that reached a maximum in the LBE-affected zone. An EPMA elemental mapping of the transition zone is shown in Fig. 7c. The $\mathrm{Zr}$-map shows an apparent decrease in $\mathrm{Zr}$ intensity throughout the $\mathrm{Pb} / \mathrm{Bi}$-containing zone. In order to verify the possible loss of $\mathrm{Zr}$, the $\mathrm{Zr}:(\mathrm{Al}+\mathrm{Pb}+\mathrm{Bi})$ ratio was compared to the $\mathrm{Zr}: \mathrm{Al}$ ratio in the unaffected zone, revealing a ratio of $65: 35$ and 67:33, respectively. This difference is small and close to the statistical error of the method; moreover, the measured difference in the $\mathrm{Zr}$ intensity can be partially attributed to the reduced electron and $\mathrm{X}$-ray interaction volume due to the presence 
of the two heavy elements ( $\mathrm{Pb}, \mathrm{Bi})$. Hence, EPMA does not provide concrete evidence of the suspected partial substitution of $\mathrm{Zr}$ by $\mathrm{Pb}$ and/or $\mathrm{Bi}$ in $\mathrm{Zr}_{2} \mathrm{AlC}$.

The $\mathrm{Al}:(\mathrm{Pb}+\mathrm{Bi})$ ratio in the zones that converted fully into the $\mathrm{Zr} 2(\mathrm{Al}, \mathrm{Pb}, \mathrm{Bi}) \mathrm{C}$ solid solution was determined to be 65:35, implying that $\mathrm{Al}$ remained the dominant A-element, while no further Al gradient was observed towards the sample surface. The $\mathrm{Pb}: \mathrm{Bi}$ ratio was 47:53, which is close to the eutectic LBE ratio of 45:55, suggesting no preferential replacement of $\mathrm{Al}$ by $\mathrm{Pb}$ or $\mathrm{Bi}$. The partial substitution of A-atoms resembles to a certain extend the synthesis technique recently employed to produce $\mathrm{Ti}_{3} \mathrm{AuC}_{2}$ [43]. Fashandi et al. heat-treated $\mathrm{Au}$-coated $\mathrm{Ti}_{3} \mathrm{SiC}_{2}$ for $12 \mathrm{~h}$ at $670^{\circ} \mathrm{C}$, resulting in the complete replacement of the A-element (Si) by $\mathrm{Au}$-atoms that was also accompanied by the elongation of the $c$-axis by $5.6 \%$ [43]. In the present work, approximately $1 / 3$ of the $\mathrm{Al}$ atoms were replaced by $\mathrm{Pb}$ and $\mathrm{Bi}$, and the resulting expansion along the $\mathrm{c}$-axis was also considerable. The $\mathrm{Al}:(\mathrm{Pb}+\mathrm{Bi})$ ratio was constant across the fully converted material volume, indicating an upper limit in the amount of $\mathrm{Al}$ that can be substituted by $\mathrm{Pb}$ and $\mathrm{Bi}$ at $500^{\circ} \mathrm{C}$. Additional experiments are required to find out whether the $\mathrm{Al}:(\mathrm{Pb}+\mathrm{Bi}) \approx 2: 1$ ratio in the $\mathrm{Zr}_{2}(\mathrm{Al}, \mathrm{Pb}, \mathrm{Bi}) \mathrm{C}$ solid solution is temperature-dependent, which would suggest that this atomic ratio corresponds to the solid-solubility limit of $\mathrm{Pb}+\mathrm{Bi}$ in the $\mathrm{Zr}_{2} \mathrm{AIC}$ MAX phase.

The other $\mathrm{Zr}$-Al-C grade, $\mathrm{Zr}_{3} \mathrm{AlC}_{2}$, showed significantly less $\mathrm{LBE}$ penetration into the bulk, which was limited to few localized spots. This indicates that the higher order (312) $\mathrm{Zr}_{3} \mathrm{AlC}_{2} \mathrm{MAX}$ phase compound is chemically more compatible with liquid $\mathrm{LBE}$ at $500^{\circ} \mathrm{C}$ than its lower order (211) $\mathrm{Zr}_{2} \mathrm{AIC}$ counterpart. This is also exemplified in $\left(\mathrm{Zr}_{0.8,}, \mathrm{Ti}_{0.2}\right)_{\mathrm{n}+1} \mathrm{AIC}$ : this ceramic was a mixture of 211 and 312 phases in the as-processed state, where the sandwich-like MAX phase grains were made of a brighter 312-rich core enveloped by a darker 211-based outer layer (Fig. 3). After exposure, this phase contrast was inverted (Figs. 4 and 9a) due to differences in the degree of interaction of the two MAX phase grain constituents with $L B E$, resulting in sandwich-like grains with a brighter, LBE-richer $(\mathrm{Al}:(\mathrm{Pb}+\mathrm{Bi}) \approx 76: 24)$ outer layer and a darker, LBE-poorer $(\mathrm{Al}:(\mathrm{Pb}+\mathrm{Bi})$ $\approx 82: 18$ ) core.

The TEM/STEM/EDS analysis of FIB foils extracted from seemingly unaffected by LBE areas in select MAX phase ceramics yielded interesting, material-specific results. First, the study of a random location ( $x-x^{\prime}$ in Fig. $8 a$ ) in an unaffected area of the $Z_{2}$ AlC surface revealed the subsurface segregation of $\mathrm{ZrC}$ particles (Fig. 8b). As observed in the $\mathrm{LBE}$-affected zones of $\mathrm{Zr}_{2} \mathrm{AlC}$ (Fig. 6b), ZrC is impervious to LBE dissolution attack, appearing as unaffected ZrC 'islands' in a matrix of $\mathrm{Zr}_{2}(\mathrm{Al}, \mathrm{Pb}, \mathrm{Bi}) \mathrm{C}$ laths. Hence, $\mathrm{ZrC}$ particle segregation in parts of the specimen surface protected locally the underlying MAX phase grains from LBE ingress, at least within the 1000$\mathrm{h}$ timeframe of the performed exposure. The formation of $\mathrm{ZrC}$ was impossible to suppress during processing, thereby becoming the main competing phase in the $\mathrm{Zr}_{2} \mathrm{AlC}$-based ceramic [33]. The destabilisation of the $\mathrm{Zr}_{2} \mathrm{AlC}$ phase in this ceramic yielded local segregations of $\mathrm{ZrC}$ and $\mathrm{Zr}$-Al intermetallics (typically, $\mathrm{Zr}_{2} \mathrm{Al}_{3}$, but the formation of $\mathrm{ZrAl}_{2}$ could also not be excluded [33]). EDS elemental mapping of such segregations of parasitic phases in the bulk of the $\mathrm{Zr}_{2} \mathrm{AIC}$ ceramic confirmed the coexistence of $\mathrm{ZrC}$ grains with intergranular $\mathrm{Zr}$-Al intermetallics (IMCs), even though XRD had detected $\mathrm{ZrC}$ as the only parasitic phase (Fig. 8c). The exact composition 
of these IMCs could not be determined by EDS, due to the fine grain size $(<1 \mu \mathrm{m})$ of these aggregates. As shown in Fig. 8c, LBE percolated through the cluster of ZrC particles, using the grain boundaries as ingress path; hence, one could expect that it is only a matter of time before LBE goes completely through such aggregates, affecting the underlying MAX phase grains. Moreover, LBE seemed to affect the Zr-Al IMCs, while leaving ZrC completely intact. The greater IMC susceptibility to LBE dissolution attack was also confirmed in the $\left(\mathrm{Zr}_{0.8}, \mathrm{Ti}_{0.2}\right)_{n+1} \mathrm{AlC}_{\mathrm{n}}$ ceramic: the $(\mathrm{Zr}, \mathrm{Ti})-\mathrm{Al}$ IMCs present between the $(\mathrm{Zr}, \mathrm{Ti}) \mathrm{C}$ grains close to the exposed specimen surface were fully dissolved by LBE (Fig. 9C). This finding is in agreement with the work of Heinzel et al. [15], who reported preferential LBE dissolution attack on the parasitic phases (primarily, Ti-Al IMCs) of Maxthal ${ }^{\circledR} 211$ (nominally, $\left.\mathrm{Ti}_{2} \mathrm{AIC}\right)$ that had been exposed to oxygen-containing $\left(C_{O} \approx\right.$ $10^{-8}$ mass\%) static liquid LBE at $650^{\circ} \mathrm{C}$ for $10,000 \mathrm{~h}$.

Second, the study of a random location ( $x-x^{\prime}$ in Fig. 10a) on the $\left(\mathrm{Nb}_{0.85}, \mathrm{Zr}_{0.15}\right)_{4} \mathrm{AlC}_{3}$ specimen surface revealed the formation of a thin (typically, $<1 \mu \mathrm{m}$; maximum local thickness $\sim 1.4 \mu \mathrm{m}$ ), seemingly discontinuous oxide scale. Analysis of this oxide scale at a site of maximum thickness (Fig. 10b) showed it to be Al-rich (Fig. 10d) and in the vitreous (amorphous) state (Fig. 10c). In fact, this MAX phase ceramic formed continuous $\mathrm{Nb}$-based $\left(\mathrm{Nb}_{2} \mathrm{O}_{5}\right)$ oxide scales upon its exposure to oxygen-containing ( $C_{O} \approx 5 \times 10^{-9}$ mass\%), fast-flowing liquid LBE at $500^{\circ} \mathrm{C}$ (see section 3.2). Hence, the formation of a thin and discontinuous (Al-based) oxide scale as result of its exposure to oxygen-poor $\left(C_{O}<10^{-10}\right.$ mass $\left.\%\right)$ static $\mathrm{LBE}$ at $500^{\circ} \mathrm{C}$ indicates that the oxygen potential was not sufficient to form a $\mathrm{Nb}$-based oxide, but formed an Al-based thin film instead, since $\mathrm{Al}_{2} \mathrm{O}_{3}$ is stable at very low oxygen potentials $\left(C_{O}<<10^{-15}\right.$ mass $\%$ at $500^{\circ} \mathrm{C}$ in LBE [37]). The absence of a continuous, protective oxide scale on the material surface, however, suggests that it is inherently resistant to dissolution corrosion at the considered exposure conditions.

Third, the study of a random location ( $x-x^{\prime}$ in Fig. 11a) on the Maxthal ${ }^{\circledR} 211$ specimen surface revealed the presence of an oxide scale with non-uniform thickness (typically, $<0.5 \mu \mathrm{m}$; locally, $>2.5 \mu \mathrm{m}$; Fig. 11b). In the areas where the oxide scale was thinnest, the oxide scale appeared to be Ti-based, while in areas of enhanced local thickness, it appeared to be Al-rich (Fig. 11c). The careful consideration of the EDS elemental maps of Fig. 11c suggests that the thicker (Albased or mixed Al-Ti oxides) oxide scales resulted from the oxidation of the Ti-Al IMCs that are present between the MAX phase grains. On the other hand, the thinner (Ti-based, presumably $\mathrm{TiO}_{2}$ ) oxide scales resulted from the oxidation of $\mathrm{Ti}_{2} \mathrm{AlC}$. The formation of $\mathrm{TiO}_{2}$ (rutile) oxide scales on Maxthal ${ }^{\circledR} 211$ (nominally, $\mathrm{Ti}_{2} \mathrm{AlC}$; usually, mixture of $\mathrm{Ti}_{2} \mathrm{AlC}_{1} \mathrm{Ti}_{3} \mathrm{AlC}_{2}$ and $\mathrm{TiAl}_{3}$ - see Table 2) exposed to liquid LBE has been previously reported by Heinzel et al. [15]. Moreover, the same authors observed the preferential oxidation of the parasitic phases (mainly, Ti-Al IMCs) in Maxthal ${ }^{\circledR} 211$ exposed to oxygen-containing ( $C_{O} \approx 10^{-6}$ mass\%) static liquid LBE at $550^{\circ} \mathrm{C}$ for up to $10,000 \mathrm{~h}[15]$.

In conclusion, the screening exposures of select MAX phases to oxygen-poor static liquid LBE showed a satisfactory overall compatibility with the HLM, except from a limited local interaction in the $\mathrm{Zr}_{2} \mathrm{AIC}, \mathrm{Zr}_{3} \mathrm{AlC}_{2}$ and $\left(\mathrm{Zr}_{0.8}, \mathrm{Ti}_{0.2}\right)_{n+1} \mathrm{AlC}_{\mathrm{n}}$ ceramics. The local interaction between $\mathrm{LBE}$ and $\mathrm{Zr}$ based MAX phases formed in-situ $\mathrm{Pb} / \mathrm{Bi}$-containing MAX phase solid solutions, a phenomenon meriting further in-depth investigation to be fully understood. Since the formation of $\mathrm{Pb} / \mathrm{Bi}$ - 
containing solid solutions occurred without the dissociation of the exposed Zr-based MAX phase compounds, one might assume that the LBE-affected parts of Zr-based ceramics will not lose completely their load-bearing capacity. This is in stark contrast with components made of $316 \mathrm{~L}$ austenitic stainless steels, where the dissolution-affected parts lose structural integrity in a dramatic and irreversible manner. The in-depth understanding of the liquid metal corrosion behaviour of MAX phase ceramics in contact with HLMs, e.g., LBE and Pb, can only be achieved by the systematic testing of these materials in different exposure conditions $\left(T, C_{O}\right.$, time), followed by detailed post-exposure material characterisation. This study showed a materialspecific corrosion resistance that was greatly affected by the performance of parasitic phases. This underlines the importance of phase purity for MAX phase ceramics intended for specific applications in HLM-cooled nuclear systems.

\subsection{Exposure to Fast-Flowing LBE}

Select MAX phase-based ceramics, i.e., $\left(\mathrm{Nb}_{0.85}, \mathrm{Zr}_{0.15}\right)_{4} \mathrm{AlC}_{3}$ (NZ413), $\mathrm{Zr}_{2} \mathrm{AlC}$ and $\mathrm{Zr}_{3} \mathrm{AlC}_{2}$, were exposed to oxygen-containing $\left(C_{O} \approx 5 \times 10^{-9}\right.$ mass $\left.\%\right)$, fast-flowing $(\mathrm{v} \approx 8 \mathrm{~m} / \mathrm{s})$ liquid $\mathrm{LBE}$ at $500^{\circ} \mathrm{C}$ for $1000 \mathrm{~h}$. Two different surface finishes of the NZ413 grade, i.e., ground and conventionally milled, were exposed simultaneously to study the effect of surface finish on the development of erosion damages. A (ground) $316 \mathrm{~L}$ austenitic stainless steel specimen was included in the same test, as reference structural material; this specimen was made of the $316 \mathrm{~L}$ SA solutionannealed heat (Table 2). An overview of the bulk pristine and tested materials is presented in Fig. 12, together with the surface topography of the specimens before and after exposure. Fig. 12 also provides a comparison of the surface finishes achieved by diamond wheel grinding and conventional milling for the NZ413 grade. The measured average roughness, $S_{a}$, and the maximum roughness, $S_{z}$ values for the 5 pristine and exposed specimens are given in Table 4 . Changes in the material surface roughness provide a good indication of the material loss due to erosion phenomena resulting from exposure to fast-flowing liquid LBE. Fig. 12 shows that both $\mathrm{Zr}$-Al-C MAX phases broke at the clamping point upon their removal from the test facility. This could be primarily attributed to the non-negligible amount of the brittle $\mathrm{ZrC}$ parasitic phase that was present in both MAX phase ceramics.

Table 4. Surface roughness values before and after material exposure to fast-flowing LBE.

\begin{tabular}{ccccccc}
\hline & & $Z_{2}$ AIC & $\mathbf{Z r}_{3}$ AlC & $\begin{array}{c}\text { Ground } \\
\text { NZ413 }\end{array}$ & $\begin{array}{c}\text { Milled } \\
\text { NZ413 }\end{array}$ & 316L SA \\
\hline \multirow{2}{*}{ Before exposure } & $\mathrm{S}_{\mathrm{a}}(\mu \mathrm{m})$ & 0.37 & 0.35 & 0.30 & 2.12 & 0.80 \\
\cline { 2 - 7 } & $\mathrm{S}_{\mathrm{z}}(\mu \mathrm{m})$ & 3.97 & 3.90 & 3.42 & 21.37 & 15.37 \\
\hline \multirow{2}{*}{ After exposure } & $\mathrm{S}_{\mathrm{a}}(\mu \mathrm{m})$ & 0.79 & 10.80 & 0.64 & 2.85 & 6.43 \\
\cline { 2 - 7 } & $\mathrm{S}_{\mathrm{z}}(\mu \mathrm{m})$ & 14.51 & 104.80 & 4.83 & 23.90 & 75.97 \\
\hline
\end{tabular}


The colour change and strong increase in surface roughness of $\mathrm{Zr}_{3} \mathrm{AlC}_{2}$ after exposure (Fig. 12) was attributed to severe oxidation. The $\mathrm{ZrO}_{2}$-based oxide scale that covered the specimen surface was quite porous and poorly adherent (Fig. 13b), i.e., it is expected to be incapable of protecting the substrate ceramic from further oxidation. A similar but milder oxidation was observed for $\mathrm{Zr}_{2} \mathrm{AlC}$ (Fig. 13a). No LBE penetration into the grains of both $\mathrm{Zr}$-Al-C MAX phase ceramics was detected, as opposed to their exposure to static LBE. Such difference in corrosion behaviour can be associated to differences in the exposure conditions: first, the LBE oxygen concentration was sufficient to promote oxidation in contact with moderately oxygenated $\left(C_{O}\right.$ $\approx 5 \times 10^{-9}$ mass\%) fast-flowing LBE, while suppressing it in contact with oxygen-poor $\left(C_{O}<10^{-10}\right.$ mass\%) static LBE. Moreover, the missing data from the first $300 \mathrm{~h}$ of exposure in the CORELLA do not allow a precise assessment of the effect of the initial LBE oxygen concentration on the material corrosion behaviour. Unlike the exposure to static LBE, the fast LBE flow $(v \approx 8 \mathrm{~m} / \mathrm{s})$ ensured the continuous and uniform mass transport of oxygen to the material surface, thus promoting oxide scale growth. The herein described exposure conditions resulted in oxidation as the prevailing corrosion mechanism, and despite the fact that the observed oxide scales were porous and not perfectly protective (e.g., LBE was detected locally in the oxide scale), the LBE ingress into the MAX phase grains was prevented, at least within the 1000-h timeframe of the CORELLA test. It should be noted that the enhanced surface roughness (Table 4) caused by oxidation made it difficult to accurately determine erosion damages.

The formation of a thin $(\sim 3-4 \mu \mathrm{m})$ oxide scale on the surface of the two NZ413 grades (Figs. $13 \mathrm{c}$ and $13 \mathrm{~g}$ ) is not surprising, taking into account that $\mathrm{Nb}$-based MAX phases have been reported to be prone to oxidation above $500^{\circ} \mathrm{C}$ in air [44]. The observed $\mathrm{Nb}_{2} \mathrm{O}_{5}$-based oxide scale was continuous and rather defective, especially in the case of the milled NZ413 (Fig. 13c). By contrast, a discontinuous, Al-based oxide scale formed on the surface of this ceramic during its exposure for the same amount of time (1000 h) to oxygen-poor static LBE; this can be associated with the extremely limited and non-uniform (due to the absence of mixing) oxygen supply to the material's surface under these test conditions. Apart from the thin oxide scale, no other corrosion/erosion damages were observed on the NZ413 MAX phase grades. Even the characteristic surface topology of the milled NZ413 was retained in a quasi-identical state in the exposed ceramic, while the ground surface was also found intact (Fig. 12). This indicates negligible - if any - material loss during the exposure of NZ413 to fast-flowing LBE, in strong contrast with the observed erosion damages on the $316 \mathrm{~L}$ stainless steel as result of the same exposure. The latter is confirmed in Figs. 13d-13g, which compare the post-exposure surface roughness of ground NZ413 MAX phase and 316L stainless steel specimens: the steel shows appreciable material loss, as opposed to NZ413 that appears intact. The poor performance of the $316 \mathrm{~L}$ structural steel is similar to that reported by Müller et al. [45] for a $316 \mathrm{~L}$ stainless steel exposed to oxygen-containing $\left(C_{O} \approx 10^{-6}\right.$ mass\%) flowing LBE $(v \approx 2 \mathrm{~m} / \mathrm{s})$ at $600^{\circ} \mathrm{C}$ for $2000 \mathrm{~h}$. Under such conditions, the formation of a protective oxide scale was suppressed and the $316 \mathrm{~L}$ steel disintegrated by massive ablation of the dissolution-affected zone. Similar exposure conditions (i.e., $T=500^{\circ} \mathrm{C}, C_{O} \leq 10^{-8}$ mass $\%, 1000 \mathrm{~h}$ ) to the herein reported ones have been previously reported by Lambrinou et al. [6] to promote LBE dissolution attack on the same $316 \mathrm{~L}$ 
steel heat (i.e., $316 \mathrm{~L} \mathrm{SA})$ in contact with static LBE. The high LBE flow velocity $(\mathrm{v} \approx 8 \mathrm{~m} / \mathrm{s})$ in the CORELLA test is expected to have further undermined the formation of a continuous, protective oxide scale on the steel surface and to have removed the dissolution-affected material areas, as previously observed by Müller et al. [45]. Based on these observations, it is clear that solution-annealed $316 \mathrm{~L}$ steels are not ideal structural materials for similar service conditions.

In conclusion, the screening exposure of select MAX phase ceramics (i.e., 3 of the 11 materials initially exposed to oxygen-poor, static LBE) to oxygen-containing, fast-flowing LBE at $500^{\circ} \mathrm{C}$ showed that NZ413 was the most suitable candidate material for use in conditions relevant to the pump impeller application. The findings of this work suggest that this material could remain stable in other $\mathrm{Pb}$-alloys (e.g., $\mathrm{Pb}, \mathrm{Pb}-17 \% \mathrm{Li}, \mathrm{Pb}-16 \% \mathrm{Au}$, etc.) at comparable (HLM-specific) exposure temperatures, on the condition that the HLM $C_{O}$ is sufficiently low. Systematic work is still needed to define the envelop of safe service conditions for this and other promising MAX phase-based materials.

\section{Conclusions}

In this work, different MAX phase-based ceramics were exposed to oxygen-poor static and fast-flowing liquid $\mathrm{LBE}$ at $500^{\circ} \mathrm{C}$ to assess their performance in conditions relevant to the harsh service conditions of pump impeller components in Gen-IV LFRs. First, 11 different ceramics were exposed to oxygen-poor ( $C_{O} \leq 2.2 \times 10^{-10}$ mass\%) static liquid LBE at $500^{\circ} \mathrm{C}$ for up to 3500 $h$ to evaluate their intrinsic resistance to LBE dissolution attack. The main findings of this part of the study could be summarised as follows:

1. The compatibility of the MAX phase-based ceramics with liquid LBE was, in general, good, without any signs of structural disintegration of any of the exposed ceramics. Material performance was affected by the presence of parasitic phases, in particular intermetallics and low-melting point (e.g., Sn) metallic inclusions, indicating that phase purity is an essential requirement for MAX phase ceramics intended for use in HLMcooled nuclear systems.

2. The low LBE oxygen concentration suppressed the formation of continuous, defect-free protective oxide scales. The superb resistance of specific MAX phase-based materials (e.g., $\left(\mathrm{Nb}_{0.85}, \mathrm{Zr}_{0.15}\right)_{4} \mathrm{AlC}_{3}$, Maxthal $\left.{ }^{\circledR} 211\right)$ to LBE dissolution attack suggests that they are chemically compatible with oxygen-poor LBE at high temperatures, unlike the reference $316 \mathrm{~L}$ stainless steels that suffer severe corrosion damages, often locally enhanced.

3. A mild LBE interaction was observed for $\mathrm{Ti}_{2} \mathrm{SnC}$, due to the presence of a minor amount of parasitic $\mathrm{Sn}$, which facilitated the LBE ingress due to the replacement of $\mathrm{Sn}$ by $\mathrm{Pb} / \mathrm{Bi}$.

4. The strongest $L B E$ interaction was observed for the $Z r$-rich MAX phase-based ceramics $\mathrm{Zr}_{2} \mathrm{AlC}, \mathrm{Zr}_{3} \mathrm{AlC}_{2}$ and $\left(\mathrm{Zr}_{0.8,8}, \mathrm{Ti}_{0.2}\right)_{\mathrm{n}+1} \mathrm{AlC} \mathrm{C}_{\mathrm{n}}$. In general, $\mathrm{Pb} / \mathrm{Bi}$ atoms were incorporated in the MAX phase crystal structure, resulting in an expansion of the lattice, especially along the $c$-axis. The LBE/MAX phase interaction resulted in the in-situ formation of new MAX phase solid solutions $\mathrm{Zr}_{2}(\mathrm{Al}, \mathrm{Pb}, \mathrm{Bi}) \mathrm{C}$ and $\left(\mathrm{Zr}_{0.8}, \mathrm{Ti}_{0.2}\right)_{\mathrm{n}+1} \mathrm{AlC} \mathrm{C}_{\mathrm{n}}$. Such LBE/MAX interaction is not expected to reduce the load-bearing capacity of the affected MAX phase ceramics, unlike the compromising dissolution corrosion damages observed in $316 \mathrm{~L}$ steels. 
In a second step, 3 of the $11 \mathrm{MAX}$ phase ceramics were exposed to oxygen-poor $\left(C_{O} \approx 5 \times 10^{-9}\right.$ mass $\%$ ) fast-flowing $\left(v \approx 8 \mathrm{~m} / \mathrm{s}\right.$ ) liquid $\mathrm{LBE}$ at $500^{\circ} \mathrm{C}$ for $1000 \mathrm{~h}$ to evaluate their resistance to erosion. The main findings of this part of the study could be summarised as follows:

1. None of the MAX phase-based ceramics showed clear signs of erosion damage. On the contrary, the reference 316L SA stainless steel exhibited appreciable mass loss, due to flow-assisted corrosion (erosion) effects.

2. Despite the rather low LBE oxygen concentration, oxidation was the prevailing corrosion mechanism, especially for the $\mathrm{Zr}_{3} \mathrm{AlC}_{2}$ and $\mathrm{Zr}_{2} \mathrm{AlC}$ grades. The controlled oxidation of the $\left(\mathrm{Nb}_{0.85}, \mathrm{Zr}_{0.15}\right)_{4} \mathrm{AlC}_{3}$ grade formed a relatively thin, continuous $\mathrm{Nb}_{2} \mathrm{O}_{5}$ oxide scale, irrespective of the surface finish (i.e., ground vs. conventionally milled).

3. The $\left(\mathrm{Nb}_{0.85}, \mathrm{Zr}_{0.15}\right)_{4} \mathrm{AlC}_{3}$ grade was the most stable of the 3 tested MAX phase ceramics in contact with fast-flowing, oxygen-poor liquid $L B E$, suggesting that this might be a promising candidate structural material for the pump impeller application, at least for parts expected to experience severe erosion damages (e.g., the rotor blades).

\section{Acknowledgements}

This research was partly funded by PhD grant No. 131081 of the Agency for Innovation by Science and Technology (IWT), Flanders, Belgium, by the European Atomic Energy Community's (Euratom) Seventh Framework Programme FP7/2007-2013 under grant agreement No. 604862 (FP7 MatISSE), the MYRRHA project, SCK •CEN, Belgium, and the research fund of $\mathrm{KU}$ Leuven under project GOA/15/012-SUMMA. The authors also acknowledge the financial support of the Hercules Foundation under Project AKUL/1319 (CombiS(T)EM). The performed research falls within the framework of the EERA (European Energy Research Alliance) Joint Programme on Nuclear Materials (JPNM). The authors would also like to thank W. Veulemans (KU Leuven) and J. Lim (SCK•CEN) for their assistance with material preparation and supply of oxygen sensors, respectively. All authors are grateful to $\mathrm{E}$. Ström of Kanthal AB, Sweden, for the supply of the Maxthal ${ }^{\circledR} 211$ and Maxthal ${ }^{\circledR} 312$ materials tested in this work. 


\section{References}

[1] K.L. Murty, and I. Charit, Structural materials for Gen-IV nuclear reactors: Challenges and opportunities, Journal of Nuclear Materials, vol. 383, pp. 189-195, 2008.

[2] A. Alemberti, J. Carlsson, E. Malambu, A. Orden, D. Struwe, P. Agostini, and S. Monti, European lead fast reactor-ELSY, Nuclear Engineering and Design, vol. 241, pp. 3470-3480, 2011.

[3] L. Mansur, A. Rowcliffe, R. Nanstad, S. Zinkle, W. Corwin, and R. Stoller, Materials needs for fusion, Generation IV fission reactors and spallation neutron sources-similarities and differences, Journal of Nuclear Materials, vol. 329, pp. 166-172, 2004.

[4] J. Van den Bosch, R.-W. Bosch, D. Sapundjiev, and A. Almazouzi, Liquid metal embrittlement susceptibility of ferritic-martensitic steel in liquid lead alloys, Journal of Nuclear Materials, vol. 376, pp. 322-329, 2008.

[5] P. Hosemann, D. Frazer, E. Stergar, and K. Lambrinou, Twin boundary-accelerated ferritization of austenitic stainless steels in liquid lead-bismuth eutectic, Scripta Materialia, vol. 118, pp. 37-40, 2016.

[6] K. Lambrinou, E. Charalampopoulou, T. Van der Donck, R. Delville, and D. Schryvers, Dissolution corrosion of $316 \mathrm{~L}$ austenitic stainless steels in contact with static liquid lead-bismuth eutectic (LBE) at $500{ }^{\circ} \mathrm{C}$, Journal of Nuclear Materials, vol. 490, pp. 9-27, 2017.

[7] J. Zhang, A review of steel corrosion by liquid lead and lead-bismuth, Corrosion Science, vol. 51, pp. 12071227, 2009.

[8] I.V. Gorynin, G.P. Karzov, V.G. Markov, and V.A. Yakovlev, Structural materials for atomic reactors with liquid metal heat-transfer agents in the form of lead or lead-bismuth alloy, Metal Science and Heat Treatment, vol. 41, pp. 384-388, 1999.

[9] G. Ilinčev, Research results on the corrosion effects of liquid heavy metals $\mathrm{Pb}, \mathrm{Bi}$ and $\mathrm{Pb}-\mathrm{Bi}$ on structural materials with and without corrosion inhibitors, Nuclear Engineering and Design, vol. 217, pp. 167-177, 2002.

[10] M.W. Barsoum, The $M_{n+1} A X_{n}$ phases: A new class of solids: Thermodynamically stable nanolaminates, Progress in Solid State Chemistry, vol. 28, pp. 201-281, 2000.

[11] D.J. Tallman, L. He, J. Gan, E.N. Caspi, E.N. Hoffman, and M.W. Barsoum, Effects of neutron irradiation of $\mathrm{Ti}_{3} \mathrm{SiC}_{2}$ and $\mathrm{Ti}_{3} \mathrm{AlC}_{2}$ in the $121-1085^{\circ} \mathrm{C}$ temperature range, Journal of Nuclear Materials, vol. 484, pp. 120-134, 2017.

[12] M. W. Barsoum, and T. El-Raghy, Synthesis and Characterization of a Remarkable Ceramic: $\mathrm{Ti}_{3} \mathrm{SiC}_{2}$, Journal of the American Ceramic Society, vol. 79, pp. 1953-1956, 1996.

[13] C. Ang, C.M. Parish, C. Shih, C. Silva, and Y. Katoh, Microstructure and mechanical properties of titanium aluminum carbides neutron irradiated at $400-700{ }^{\circ} \mathrm{C}$, Journal of the European Ceramic Society, vol. 37, pp. $2353-$ 2363, 2017.

[14] A. K. Rivai, and M. Takahashi, Compatibility of surface-coated steels, refractory metals and ceramics to high temperature lead-bismuth eutectic, Progress in Nuclear Energy, vol. 50, pp. 560-566, 2008.

[15] A. Heinzel, A. Weisenburger, and G. Müller, Long-term corrosion tests of $\mathrm{Ti}_{3} \mathrm{SiC}_{2}$ and $\mathrm{Ti}_{2} \mathrm{AlC}$ in oxygen containing LBE at temperatures up to $700{ }^{\circ} \mathrm{C}$, Journal of Nuclear Materials, vol. 482, pp. 114-123, 2016.

[16] A. Heinzel, G. Müller, and A. Weisenburger, Compatibility of $\mathrm{Ti}_{3} \mathrm{SiC}_{2}$ with liquid $\mathrm{Pb}$ and $\mathrm{PbBi}$ containing oxygen, Journal of Nuclear Materials, vol. 392, pp. 255-258, 2009.

[17] L.A. Barnes, N.L. Dietz Rago, and L. Leibowitz, Corrosion of ternary carbides by molten lead, Journal of Nuclear Materials, vol. 373, pp. 424-428, 2008.

[18] M. Utili, M. Agostini, G. Coccoluto, and E. Lorenzini, $\mathrm{Ti}_{3} \mathrm{SiC}_{2}$ as a candidate material for lead cooled fast reactor, Nuclear Engineering and Design, vol. 241, pp. 1295-1300, 2011.

[19] H. Aït-Abderrahim, D. De Bruyn, G. Van den Eynde, and S. Michiels, Transmutation of high-level nuclear waste by means of accelerator driven system, R. Stock (Ed.), Encyclopedia of Nuclear Physics and its Applications, first ed., Wiley-VCH Verlag GmbH \& Co. KGaA, 2013, pp. 689-704.

[20] K. Lambrinou, T. Lapauw, A. Jianu, A. Weisenburger, J. Ejenstam, P. Szakálos, J. Wallenius, E. Ström, K. Vanmeensel, and J. Vleugels, Corrosion-Resistant Nano-Laminated Ternary Carbides for use in Heavy Liquid Metal Coolants, 39th International Conference \& Expo on Advanced Ceramics \& Composites (ICACC 2015), pp. 1-15, 2015. [21] G.W. Bentzel, M. Ghidiu, J. Griggs, A. Lang, and M.W. Barsoum, On the interactions of Ti ${ }_{2} \mathrm{AlC}_{1} \mathrm{Ti}_{3} \mathrm{AlC}_{2}, \mathrm{Ti}_{3} \mathrm{SiC}_{2}$ and $\mathrm{Cr}_{2} \mathrm{AlC}$ with pure sodium at $550^{\circ} \mathrm{C}$ and $750^{\circ} \mathrm{C}$, Corrosion Science, vol. 111, pp. 568-573, 2016. 
[22] W. Jeitschko, H. Nowotny, and F. Benesovsky, Die H-Phasen $\mathrm{Ti}_{2} \mathrm{TIC}_{1} \mathrm{Ti}_{2} \mathrm{PbC}, \mathrm{Nb}_{2} \mathrm{InC}, \mathrm{Nb}_{2} \mathrm{SnC}$ und $\mathrm{Ta}_{2} \mathrm{GaC}_{1}$ Monatshefte für Chemie und verwandte Teile anderer Wissenschaften, vol. 95, pp. 431-435, 1964.

[23] C. Grove, D. Shepherd, M. Thomas, and P. Little, Neutronics of MAX phase materials, Proceedings SMINS4, 11-14 July 2016, Manchester, UK, pp. 1-14, 2016.

[24] G. Müller, A. Heinzel, G. Schumacher, and A. Weisenburger, Control of oxygen concentration in liquid lead and lead-bismuth, Journal of Nuclear Materials, vol. 321, pp. 256-262, 2003.

[25] T. Lapauw, K. Vanmeensel, K. Lambrinou, and J. Vleugels, Rapid synthesis and elastic properties of finegrained $\mathrm{Ti}_{2} \mathrm{SnC}$ produced by spark plasma sintering, Journal of Alloys and Compounds, vol. 631, pp. 72-76, 2015.

[26] J. Lim, A. Mariën, K. Rosseel, A. Aerts, and J. Van den Bosch, Accuracy of potentiometric oxygen sensors with $\mathrm{Bi} / \mathrm{Bi}_{2} \mathrm{O}_{3}$ reference electrode for use in liquid LBE, Journal of Nuclear Materials, vol. 429, pp. 270-275, 2012.

[27] E. Yamaki, K. Ginestar, L. Martinelli, Dissolution mechanism of $316 \mathrm{~L}$ in lead-bismuth eutectic at $500{ }^{\circ} \mathrm{C}$, Corrosion Science, vol. 53, pp. 3075-3085, 2011.

[28] G. Coen, J. Van den Bosch, A. Almazouzi, and J. Degrieck, Investigation of the effect of lead-bismuth eutectic on the fracture properties of T91 and 316L, Journal of Nuclear Materials, vol. 398, pp. 122-128, 2010.

[29] X. Gong, P. Marmy, A. Volodin, B. Amin-Ahmadi, L. Qin, D. Schryvers, S. Gavrilov, E. Stergar, B. Verlinden, M. Wevers, and M. Seefeldt, Multiscale investigation of quasi-brittle fracture characteristics in a $9 \mathrm{Cr}-1 \mathrm{Mo}$ ferriticmartensitic steel embrittled by liquid lead-bismuth under low cycle fatigue, Corrosion Science, vol. 102, pp. 137$152,2016$.

[30] M. Kieser, H. Muscher, A. Weisenburger, A. Heinzel, and G. Müller, Liquid metal corrosion/erosion investigations of structure materials in lead cooled systems: Part 1, Journal of Nuclear Materials, vol. 392, pp. 405412, 2009.

[31] T. Lapauw, K. Vanmeensel, K. Lambrinou, and J. Vleugels, A new method to texture dense $M_{n+1} A X_{n}$ ceramics by spark plasma deformation, Scripta Materialia, vol. 111, pp. 98-101, 2016.

[32] T. Lapauw, D. Tytko, K. Vanmeensel, S. Huang, P.-P. Choi, D. Raabe, E.N. Caspi, O. Ozeri, M. to Baben, J.M. Schneider, K. Lambrinou, and J. Vleugels, $\left(\mathrm{Nb}_{x}, \mathrm{Zr}_{1-\mathrm{x}}\right)_{4} \mathrm{AlC}_{3} \mathrm{MAX}$ Phase Solid Solutions: Processing, Mechanical Properties, and Density Functional Theory Calculations, Inorganic Chemistry, vol. 55, pp. 5445-5452, 2016.

[33] T. Lapauw, K. Lambrinou, T. Cabioc'h, J. Halim, J. Lu, A. Pesach, O. Rivin, O. Ozeri, E.N. Caspi, L. Hultman, P. Eklund, J. Rosén, M.W. Barsoum, and J. Vleugels, Synthesis of the new MAX phase $\mathrm{Zr}_{2} \mathrm{AIC}$, Journal of the European Ceramic Society, vol. 36, pp. 1847-1853, 2016.

[34] T. Lapauw, J. Halim, J. Lu, T. Cabioc'h, L. Hultman, M.W. Barsoum, K. Lambrinou, and J. Vleugels, Synthesis of the novel $\mathrm{Zr}_{3} \mathrm{AlC}_{2}$ MAX phase, Journal of the European Ceramic Society, vol. 36, pp. 943-947, 2016.

[35] B. Tunca, T. Lapauw, O.M. Karakulina, M. Batuk, T. Cabioc'h, J. Hadermann, R. Delville, K. Lambrinou, and J. Vleugels, Synthesis of MAX Phases in the Zr-Ti-Al-C System, Inorganic Chemistry, vol. 56, pp. 3489-3498, 2017.

[36] C. Hu, Y. Sakka, S. Grasso, T. Nishimura, S. Guo, and H. Tanaka, Shell-like nanolayered $\mathrm{Nb}_{4} \mathrm{AlC}_{3}$ ceramic with high strength and toughness, Scripta Materialia, vol. 64, pp. 765-768, 2011.

[37] C. Schroer, and J. Konys, Physical chemistry of corrosion and oxygen control in liquid lead and lead-bismuth eutectic, Wissenschaftlische Berichte FZKA 7364, Forschungszentrum Karlsruhe in der Helmholtz-Gemeinschaft, December 2007.

[38] D. Horlait, S. Grasso, A. Chroneos, and W.E. Lee, Attempts to synthesise quaternary MAX phases $(\mathrm{Zr}, \mathrm{M})_{2} \mathrm{AlC}$ and $\mathrm{Zr}_{2}(\mathrm{Al}, \mathrm{A}) \mathrm{C}$ as a way to approach $\mathrm{Zr}_{2} \mathrm{AlC}$, Materials Research Letters, vol. 4, pp. 1-8, 2016.

[39] D. Horlait, S. C. Middleburgh, A. Chroneos, and W.E. Lee, Synthesis and DFT investigation of new bismuthcontaining MAX phases, Scientific Reports, vol. 6, p. 18829, 2016.

[40] W. Jeitschko, H. Nowotny, and F. Benesovsky, Carbides of formula $T_{2} M C$, Journal of the Less Common Metals, vol. 7, pp. 133-138, 1964.

[41] T. El-Raghy, S. Chakraborty, and M.W. Barsoum, Synthesis and characterization of $\mathrm{Hf}_{2} \mathrm{PbC}, \mathrm{Zr}_{2} \mathrm{PbC}$ and $\mathrm{M}_{2} \mathrm{SnC}(\mathrm{M}=\mathrm{Ti}, \mathrm{Hf}, \mathrm{Nb}$ or Zr), Journal of the European Ceramic Society, vol. 20, pp. 2619-2625, 2000.

[42] M.W. Barsoum, MAX Phases: Properties of Machinable Ternary Carbides and Nitrides: Wiley-VCH Verlag GmbH \& Co., 2013. 
[43] H. Fashandi, M. Dahlqvist, J. Lu, J. Palisaitis, S.I. Simak, I.A. Abrikosov, J. Rosén, L. Hultman, M. Andersson, A.L. Spetz, and P. Eklund, Synthesis of $\mathrm{Ti}_{3} \mathrm{AuC}_{2}, \mathrm{Ti}_{3} \mathrm{Au}_{2} \mathrm{C}_{2}$ and $\mathrm{Ti}_{3} I r \mathrm{C}_{2}$ by noble metal substitution reaction in $\mathrm{Ti}_{3} \mathrm{SiC}_{2}$ for high-temperature-stable Ohmic contacts to SiC, Nature Materials, vol. 16, pp. 814-818, 2017.

[44] L. Zheng, J. Wang, and Y. Zhou, Improving the High-Temperature Oxidation Resistance of $\mathrm{Nb}_{4} \mathrm{AlC}_{3}$ by Silicon Pack Cementation, Journal of the American Ceramic Society, vol. 97, pp. 552-561, 2014.

[45] G. Müller, A. Heinzel, J. Konys, G. Schumacher, A. Weisenburger, F. Zimmermann, V. Engelko, A. Rusanov, and V. Markov, Results of steel corrosion tests in flowing liquid $\mathrm{Pb} / \mathrm{Bi}$ at $420-600^{\circ} \mathrm{C}$ after $2000 \mathrm{~h}$, Journal of Nuclear Materials, vol. 301, pp. 40-46, 2002. 


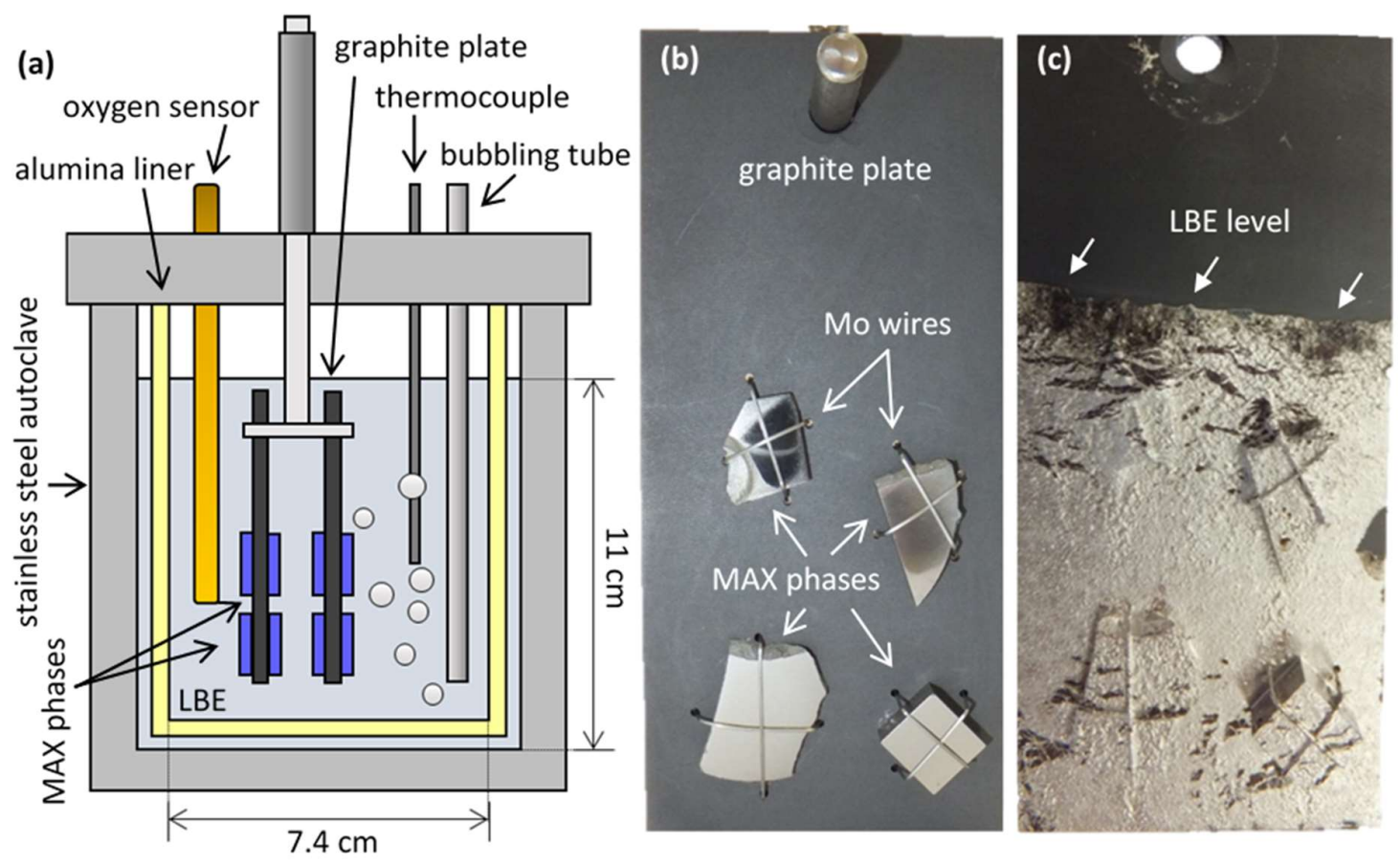

Fig. 1. (a) Experimental setup used to expose MAX phase ceramics to oxygen-poor, static LBE. One of the graphite plates used to immerse the MAX phase ceramics in the LBE bath prior to (b) and after (c) the $3500 \mathrm{~h}$-long exposure to oxygen-poor $\left(C_{O}<10^{-10}\right.$ mass\%) liquid LBE at $500^{\circ} \mathrm{C}$. 


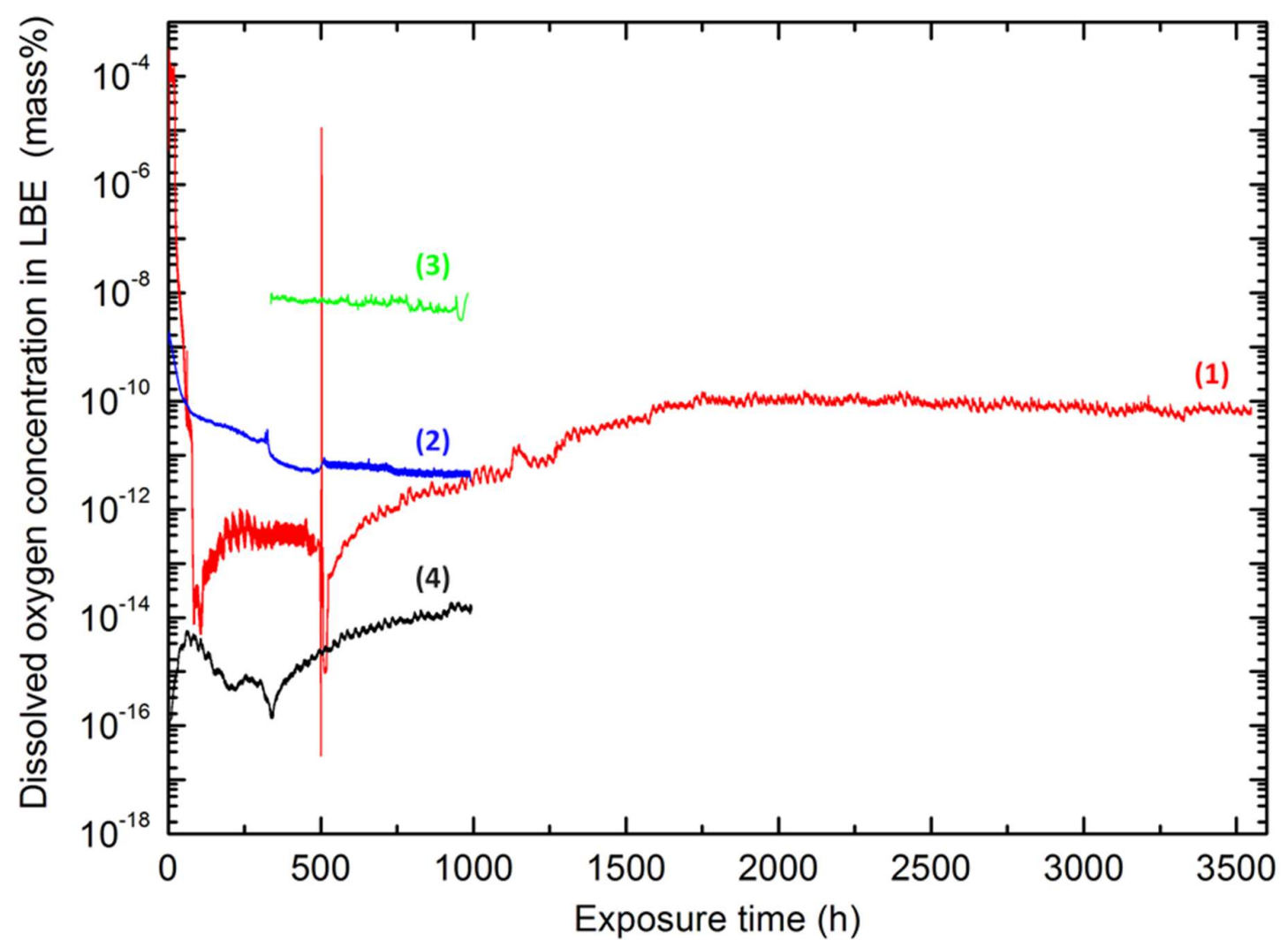

Fig. 2. Evolution of the dissolved oxygen concentration in liquid LBE during the exposures performed in this work. Plots (1), (2) and (4) refer to tests in static LBE, and plot (3) to testing in fast-flowing LBE. 


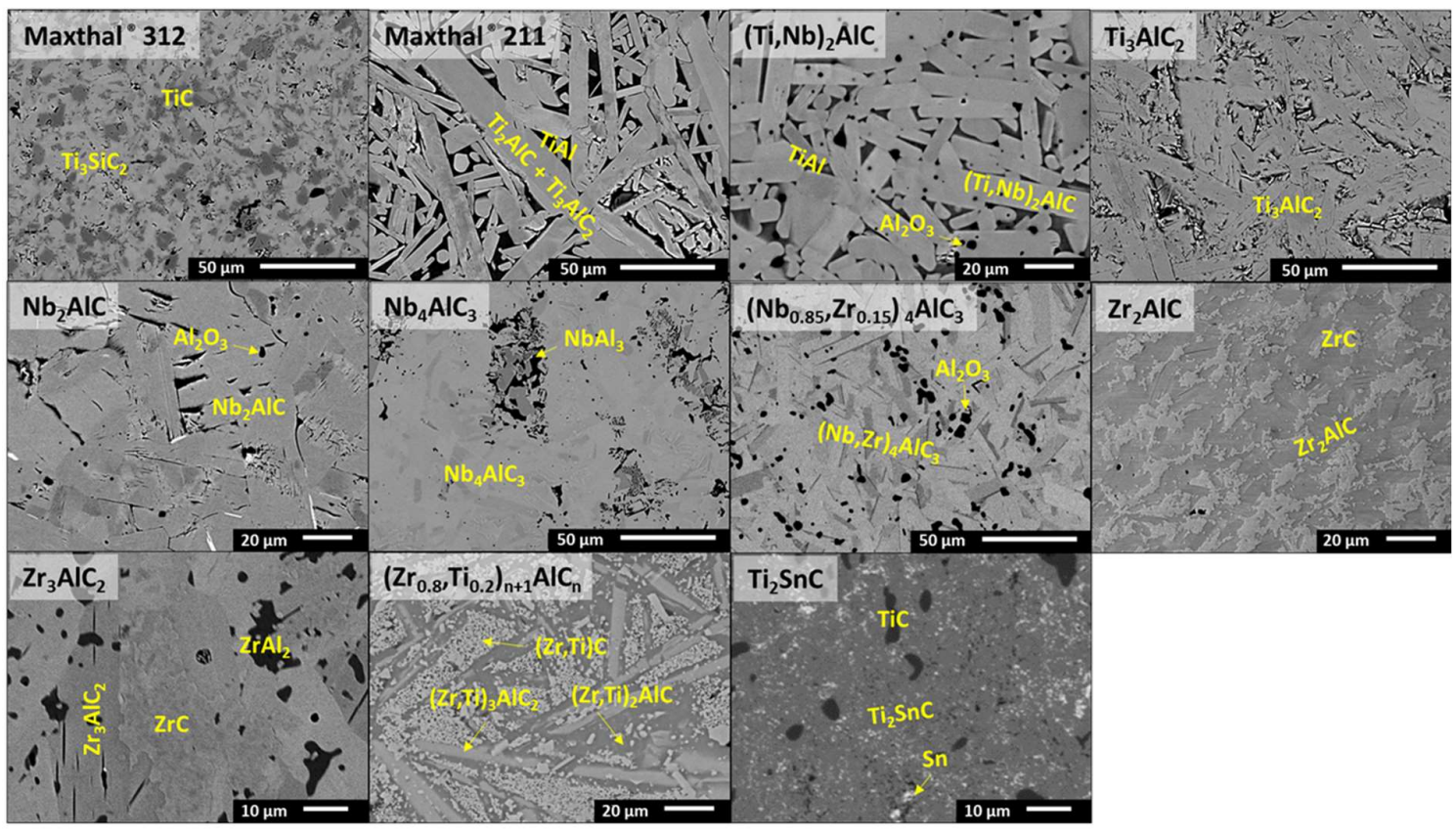

Fig. 3. Backscattered electron (BSE) images of the pristine MAX phase ceramics, indicating all parasitic phases. 


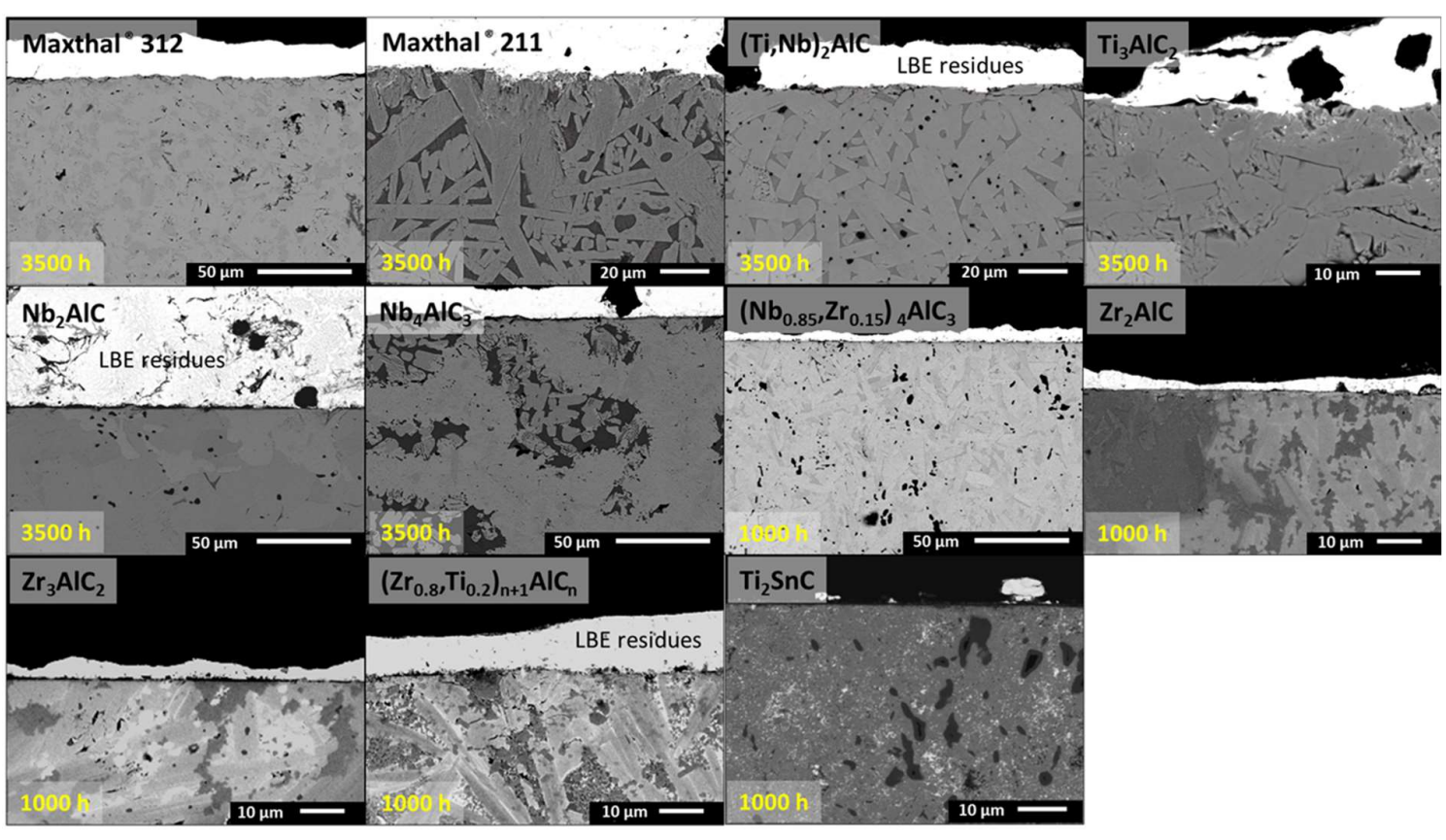

Fig. 4. $B S E$ images of the $L B E / M A X$ phase interaction for all MAX phase ceramics exposed to static LBE for different times. 


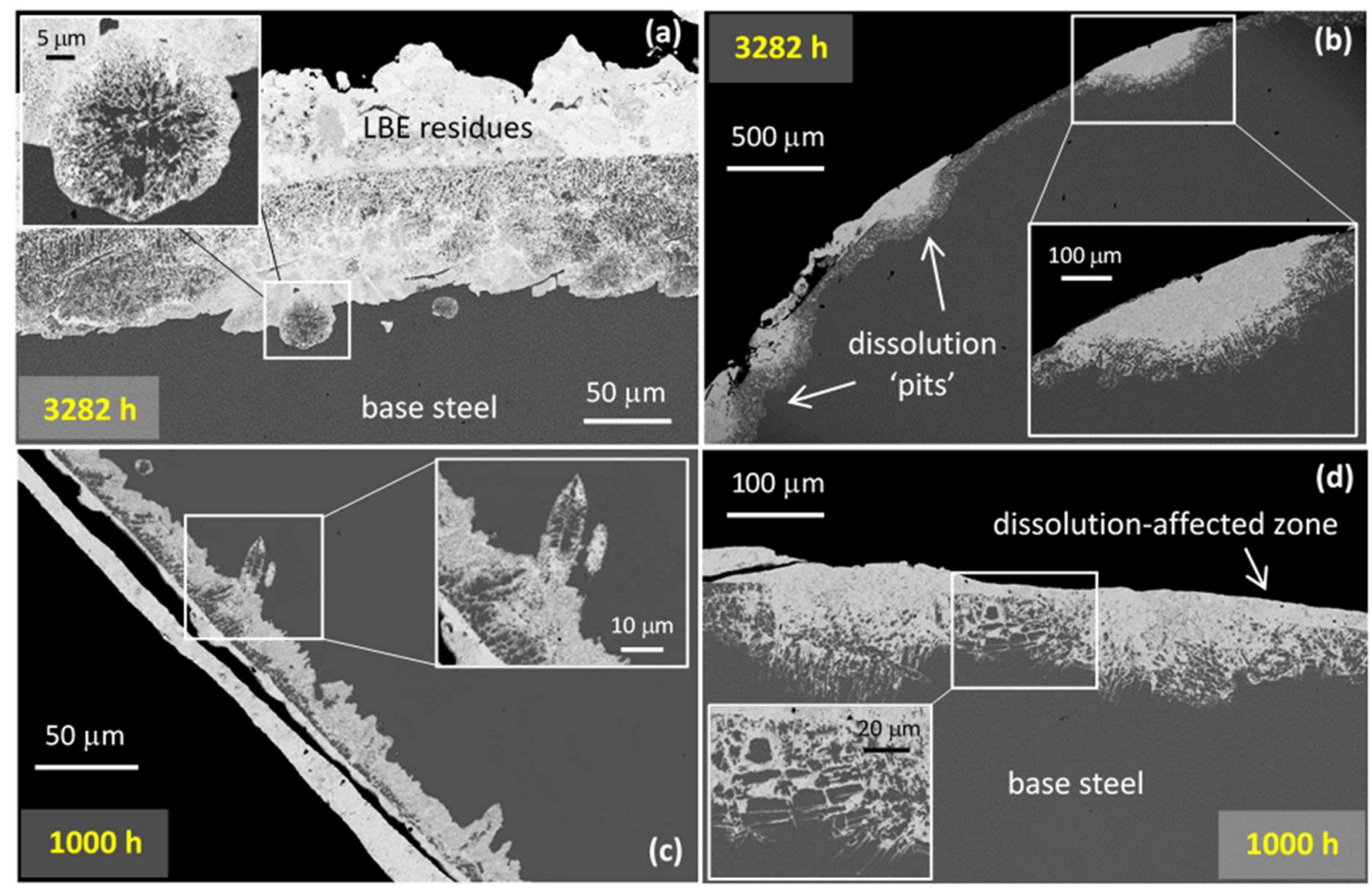

Fig. 5. BSE images showing dissolution corrosion damages observed in $316 \mathrm{~L}$ stainless steels exposed to oxygen-poor $\left(C_{O} \leq 10^{-8}\right.$ mass $\left.\%\right)$ static $\mathrm{LBE}$, at $500^{\circ} \mathrm{C}$ for $1000-3282 \mathrm{~h}:(\mathrm{a}, \mathrm{c}) 316 \mathrm{~L} \mathrm{SA}$ steel; (b,d) 316L CW steel. 


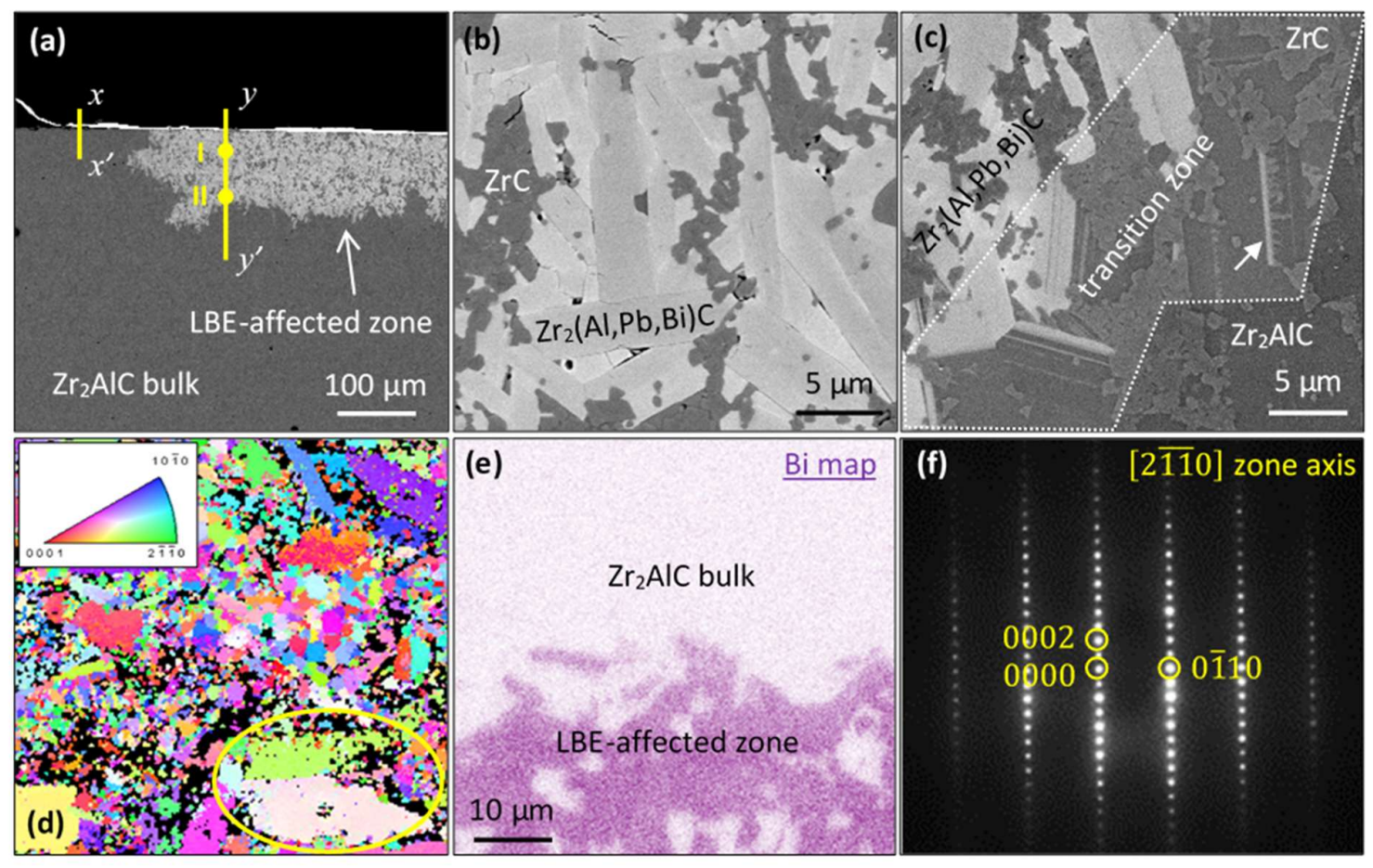

Fig. 6. BSE images of the $\mathrm{Zr}_{2} \mathrm{AlC}$-based ceramic exposed for $1000 \mathrm{~h}$ to oxygen-poor, static LBE: (a) non-uniform attack, showing LBE-affected areas next to seemingly unaffected areas, (b) area in the centre of the LBE-affected zone (site I in Fig. 6a), (c) area at the $\mathrm{Zr}_{2} \mathrm{AlC} / \mathrm{LBE}$ interaction front (site II in Fig. 6a). (d) EBSD grain orientation map and (e) respective EDS Bi map of a location close to the $Z r_{2} A I C / L B E$ interaction front. (f) SAED pattern showing the preservation of the MAX phase crystal structure in the LBE-affected zone of $\mathrm{Zr}_{2} \mathrm{AIC}$. 

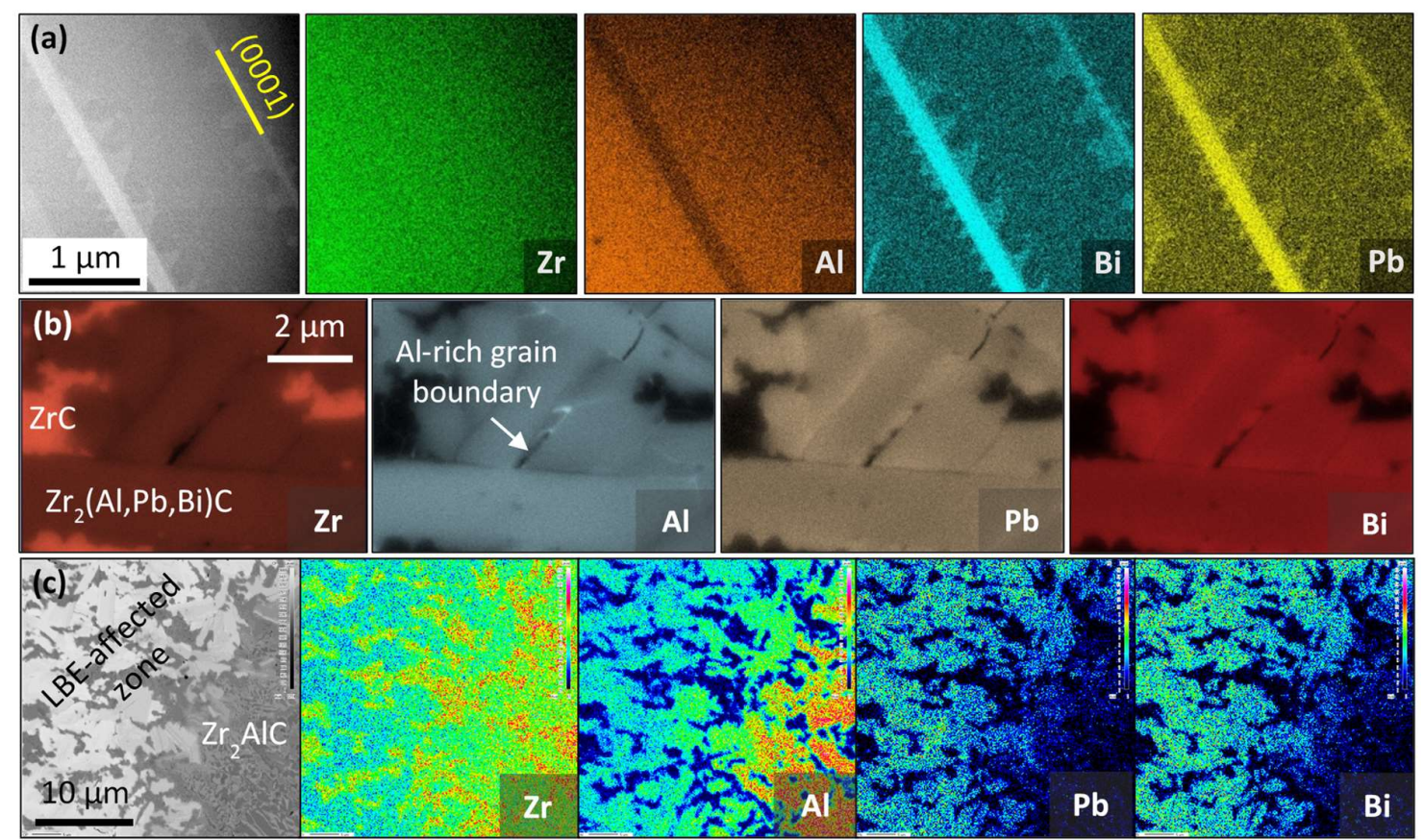

Fig. 7. (a) EDS elemental maps showing $\mathrm{Pb} / \mathrm{Bi}$ diffusion away from the basal planes in the $\mathrm{Zr}_{2} \mathrm{AlC}$-based ceramic. (b) EDS elemental maps of $\mathrm{Zr}_{2}(\mathrm{Al}, \mathrm{Pb}, \mathrm{Bi}) \mathrm{C}$ MAX phase grains: Al-rich grain boundaries and chemically inert $\mathrm{ZrC}$ grains. (c) EPMA elemental mapping close to the $\mathrm{Zr}_{2} \mathrm{AIC} / \mathrm{LBE}$ interaction front. 

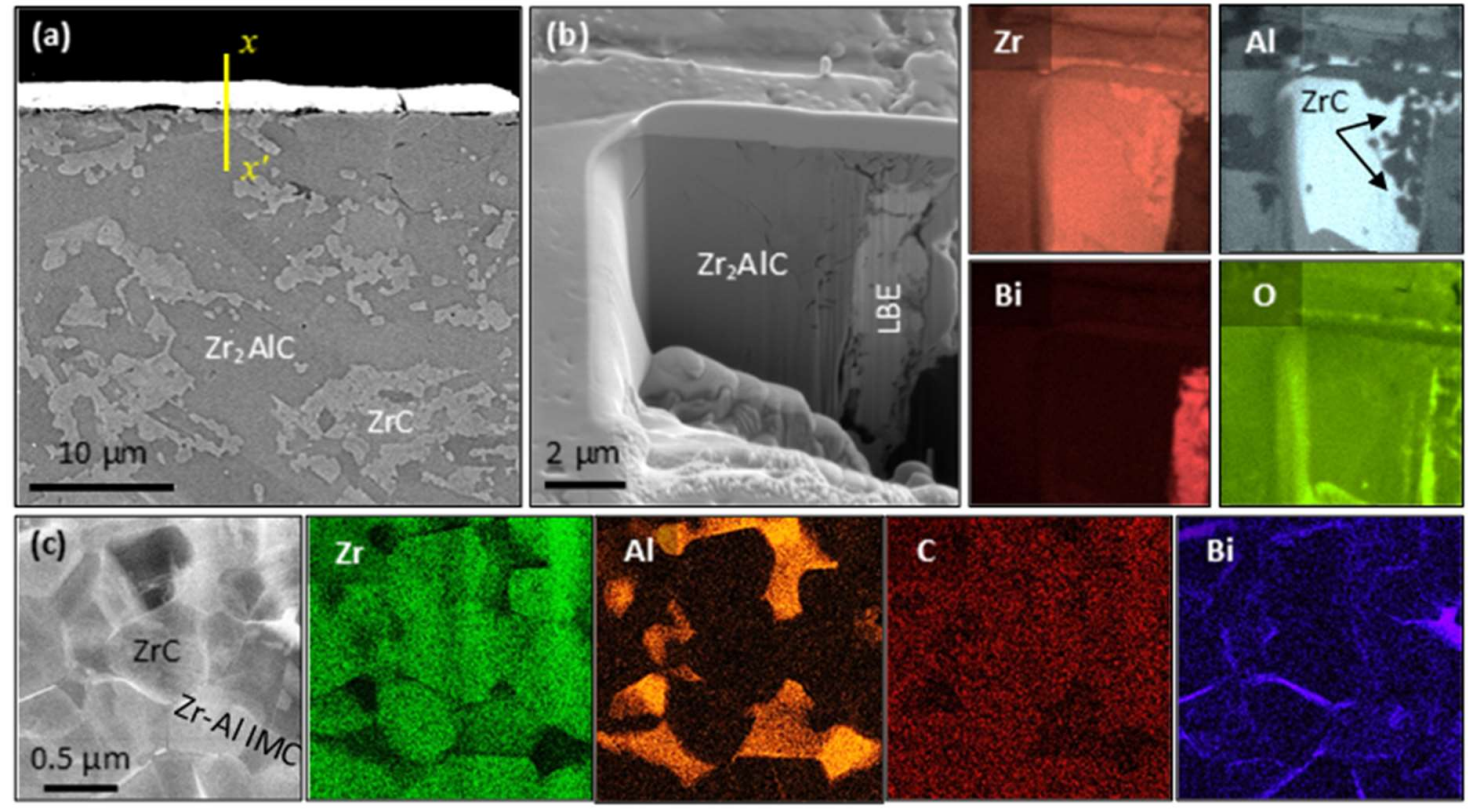

Bi

Fig. 8. (a) BSE image of a non-attacked area in the $\mathrm{Zr}_{2} \mathrm{AlC}$-based ceramic exposed to $1000 \mathrm{~h}$ to oxygen-poor, static LBE. (b) FIB cross-section along $x-x^{\prime}$ in Fig. 8a and EDS elemental maps showing segregation of $\mathrm{ZrC}$ particles at the specimen surface. (c) Segregation of $\mathrm{ZrC}$ particles in an LBE-affected zone: LBE penetrates intergranularly in this biphasic area (made of ZrC and Zr-Al IMCs), leaving ZrC intact. 


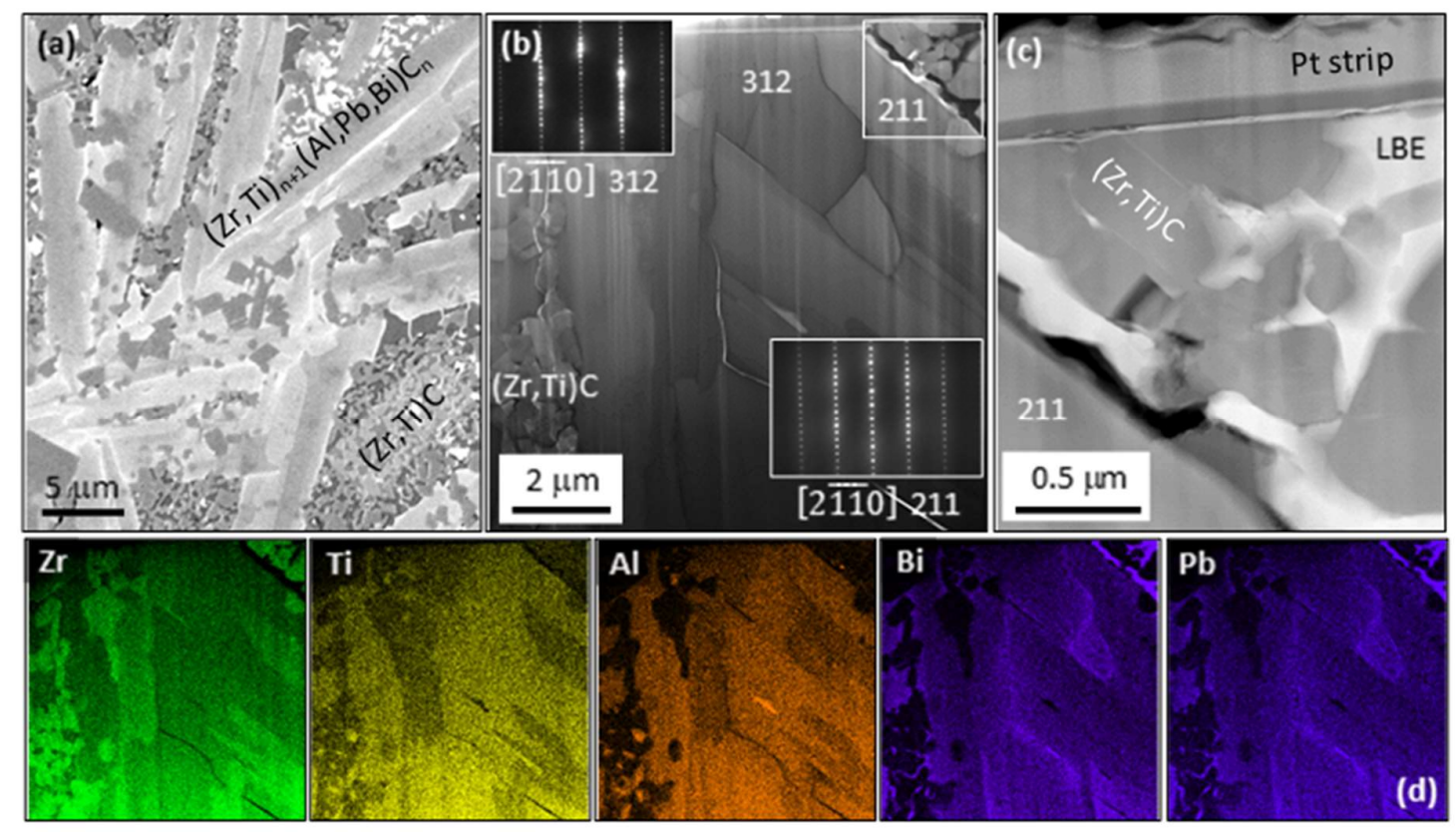

Fig. 9. (a) BSE image of the $\left(\mathrm{Zr}_{0.8}, \mathrm{Ti}_{0.2}\right)_{\mathrm{n}+1} \mathrm{Al} \mathrm{C}_{\mathrm{n}}$-based ceramic exposed for $1000 \mathrm{~h}$ to oxygenpoor, static LBE. (b) HAADF STEM image of an area containing 312 and 211 MAX phase and

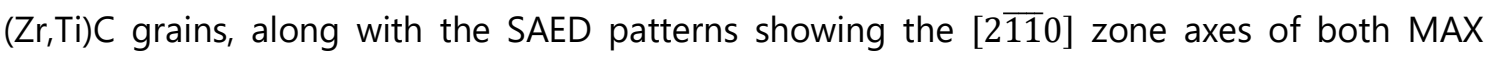
phases. (c) HAADF STEM image of the area at the upper right corner of Fig. 9b: LBE penetration into $(\mathrm{Zr}, \mathrm{Ti}) \mathrm{C}$ grain boundaries and LBE dissolution attack of the Zr-AI IMCs. (d) STEM EDS elemental maps of the whole area shown in Fig. 9b. 

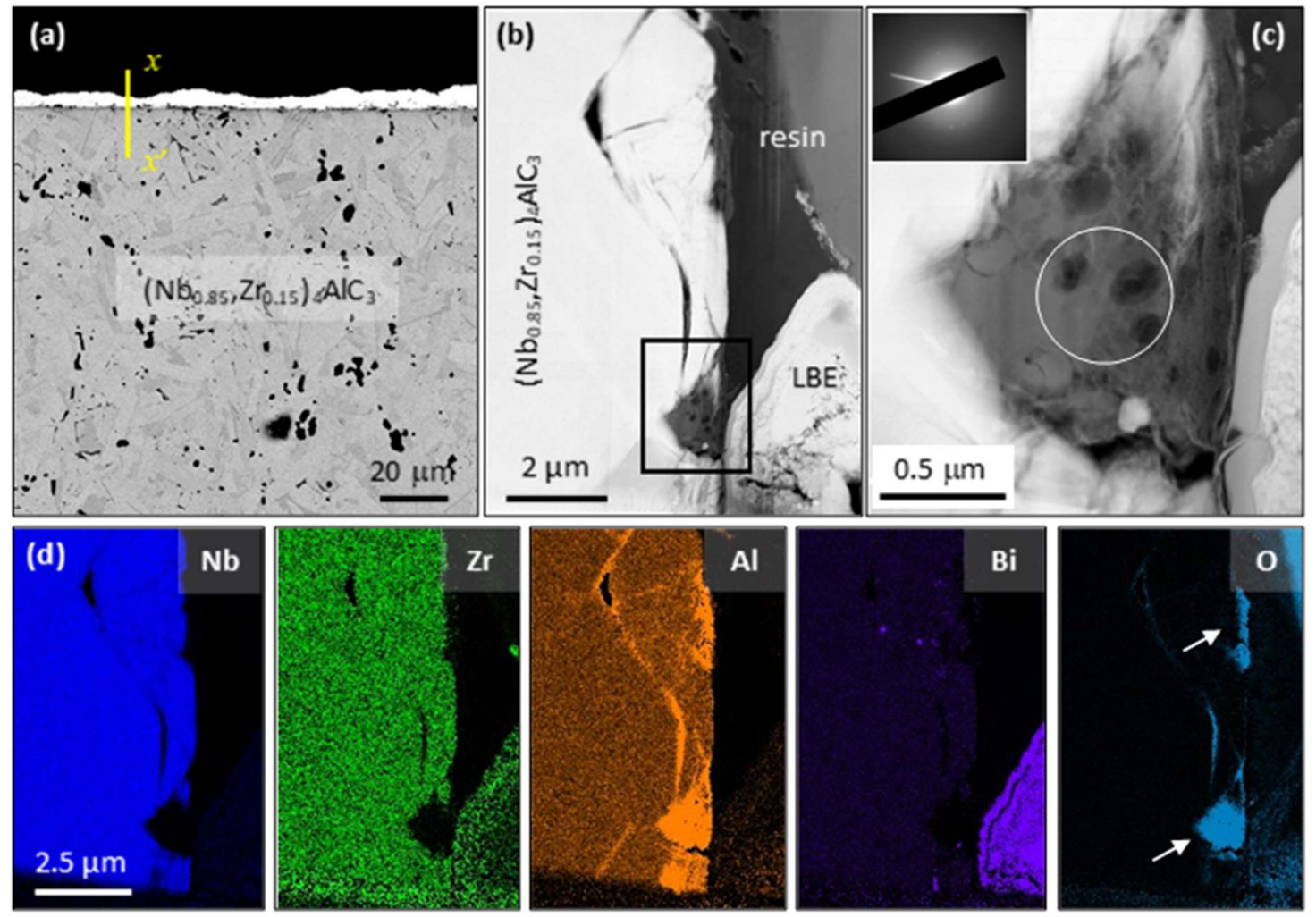

Fig. 10. (a) $B S E$ image of the $\left(\mathrm{Nb}_{0.85}, \mathrm{Zr}_{0.15}\right)_{4} \mathrm{AlC} \mathrm{C}_{3}$-based ceramic exposed for $1000 \mathrm{~h}$ to oxygenpoor static LBE. (b) HAADF STEM image of a FIB foil extracted from position $x-x^{\prime}$ in Fig. 10a showing the presence of an oxide-filled pocket at the LBE/MAX phase interface. (c) HAADF STEM image of the oxide-filled pocket and accompanying SAED pattern revealing that the oxide is in the vitreous (amorphous) state. (d) STEM EDS elemental maps of the area shown in Fig. 10b showing the presence of thin, seemingly non-continuous oxides (arrows) on the specimen surface. 

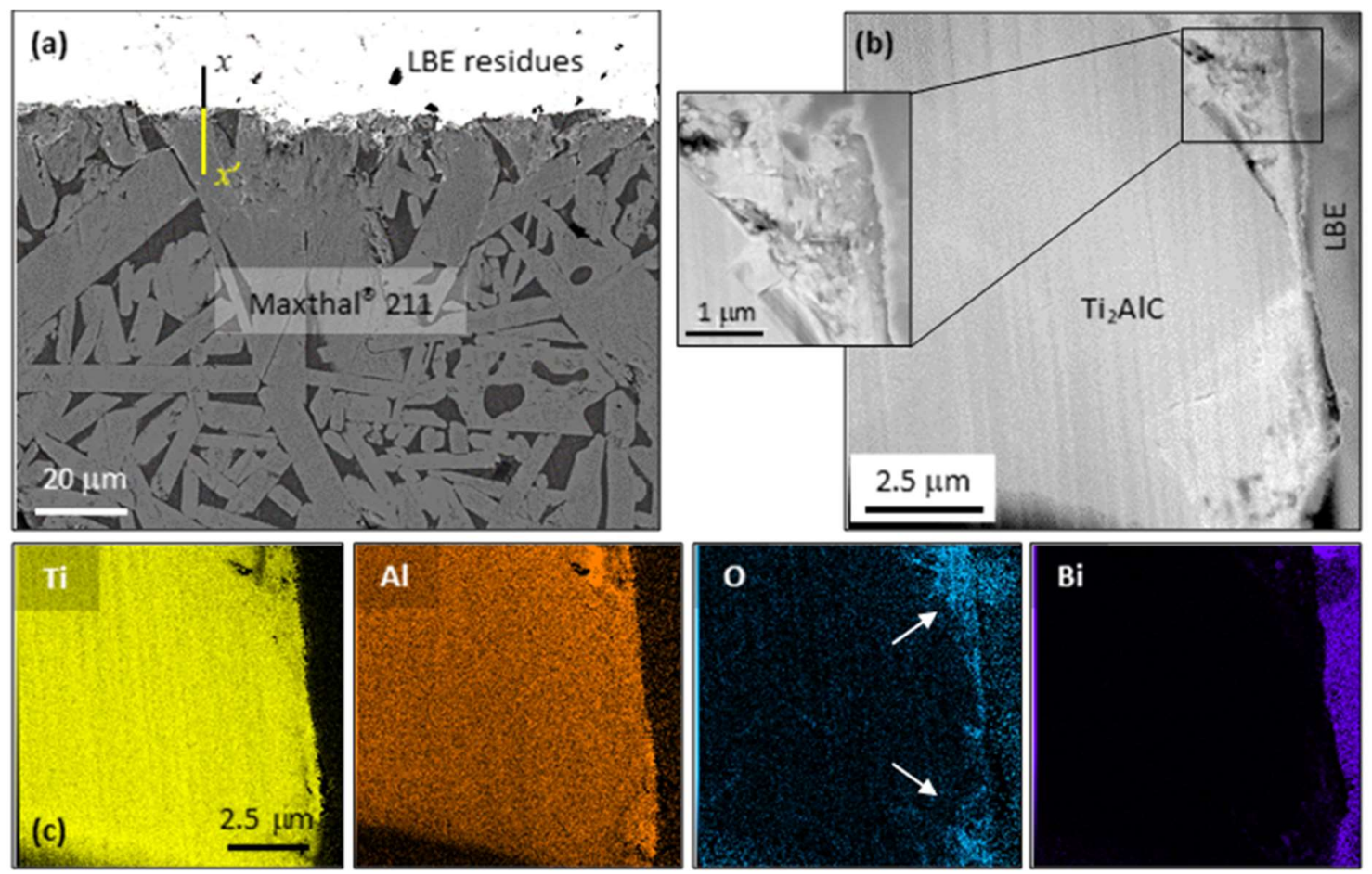

Fig. 11. (a) BSE image of the Maxthal ${ }^{\circledR} 211$ ceramic exposed for $3500 \mathrm{~h}$ to oxygen-poor, static LBE. (b) HAADF STEM image of the FIB foil extracted from position $x-x^{\prime}$ in Fig. 11a. The magnified inset shows details from the oxide scale. (c) STEM EDS elemental maps of the area shown in Fig. 11b: the thickness of the oxide scale (arrows) is non-uniform and its continuity might be locally disrupted. 


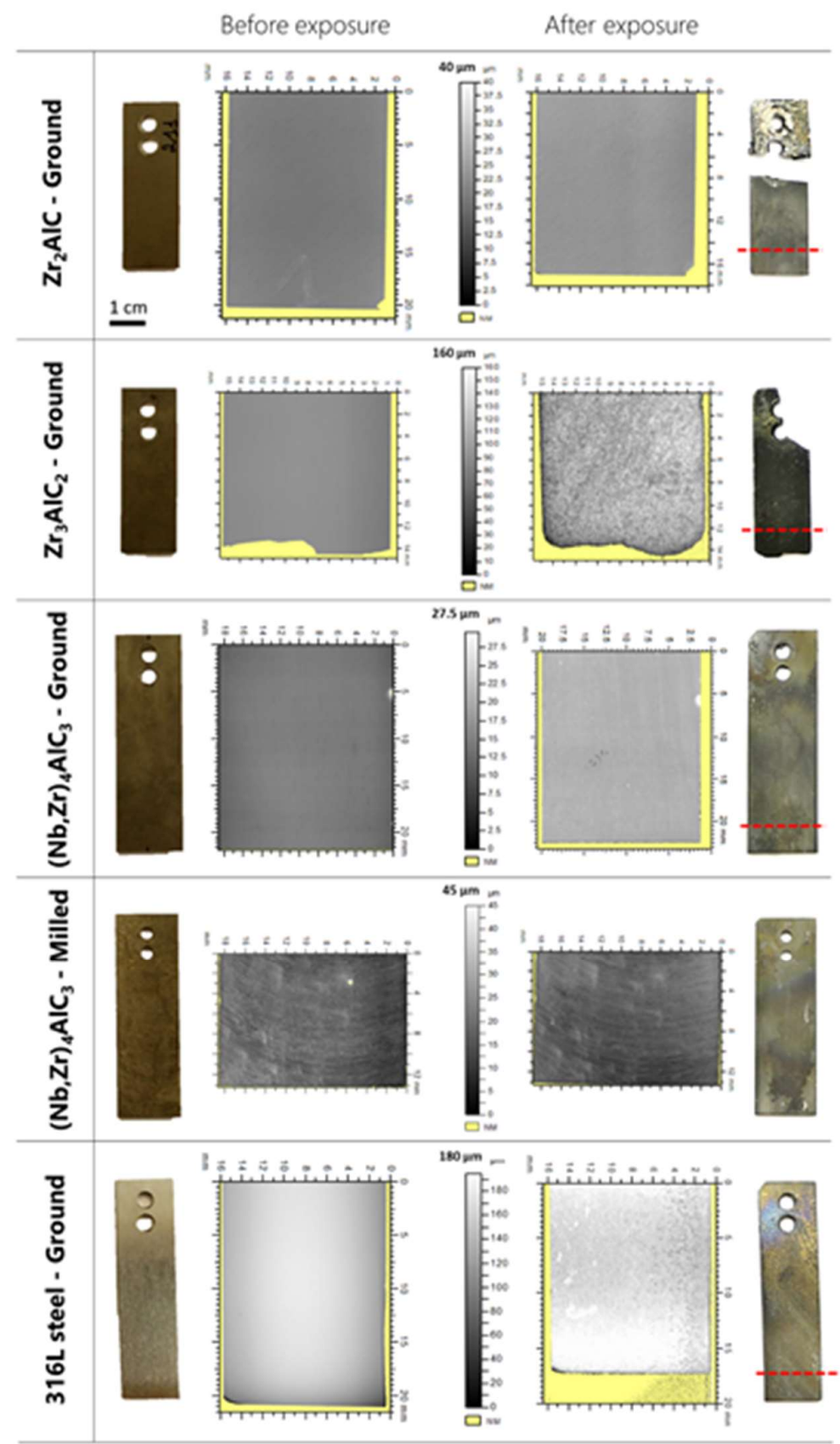

Fig. 12. Overview and profilometry data of the front specimen surfaces prior to and after exposure for $1000 \mathrm{~h}$ at $500^{\circ} \mathrm{C}$ in fast-flowing LBE. The specimens were cleaned from the LBE residues first by hot oil $\left(190^{\circ} \mathrm{C}\right)$ and then by a $1: 1: 1$ solution of $\mathrm{H}_{2} \mathrm{O}_{2}: \mathrm{C}_{2} \mathrm{H}_{5} \mathrm{OH}: \mathrm{CH}_{3} \mathrm{COOH}$. The red lines on the bulk samples after exposure indicate the location of the cross-sections shown in Fig. 13. 

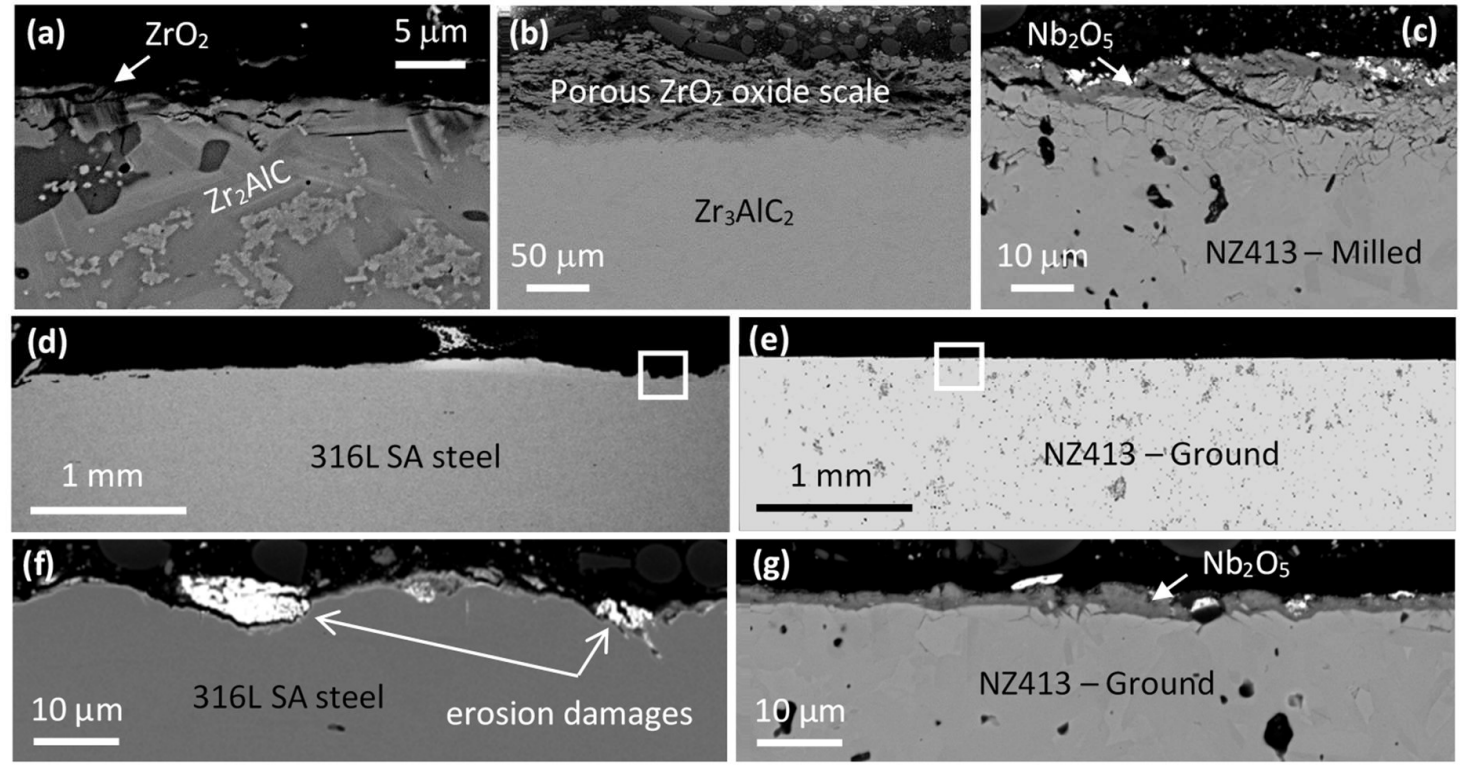

Fig. 13. $B S E$ images of materials exposed for $1000 \mathrm{~h}$ to fast-flowing $\mathrm{LBE}$ : (a) $\mathrm{Zr}_{2} \mathrm{AIC}$, (b) $\mathrm{Zr}_{3} \mathrm{AlC}_{2}$, (c) NZ413 with milled surface finish, (d) 316L SA steel - overview, (e) NZ413 with ground surface finish - overview, (f) 316L SA steel - detail, and (g) NZ413 with ground surface finish - detail. Erosion damages are visible in the $316 \mathrm{~L}$ SA stainless steel, as opposed to the unaffected NZ413 MAX phase. 